\title{
Perceived Burdensomeness in Older and Younger Adults: Evaluation of the Psychometric Properties of the Interpersonal Needs Questionnaire
}

Julie Lutz

Follow this and additional works at: https://researchrepository.wvu.edu/etd

\section{Recommended Citation}

Lutz, Julie, "Perceived Burdensomeness in Older and Younger Adults: Evaluation of the Psychometric Properties of the Interpersonal Needs Questionnaire" (2015). Graduate Theses, Dissertations, and Problem Reports. 6125.

https://researchrepository.wvu.edu/etd/6125

This Thesis is protected by copyright and/or related rights. It has been brought to you by the The Research Repository @ WVU with permission from the rights-holder(s). You are free to use this Thesis in any way that is permitted by the copyright and related rights legislation that applies to your use. For other uses you must obtain permission from the rights-holder(s) directly, unless additional rights are indicated by a Creative Commons license in the record and/ or on the work itself. This Thesis has been accepted for inclusion in WVU Graduate Theses, Dissertations, and Problem Reports collection by an authorized administrator of The Research Repository @ WVU. For more information, please contact researchrepository@mail.wvu.edu. 
Perceived Burdensomeness in Older and Younger Adults: Evaluation of the Psychometric Properties of the Interpersonal Needs Questionnaire

Julie Lutz

\author{
Thesis submitted \\ to the Eberly College of Arts and Sciences \\ at West Virginia University \\ in partial fulfillment of the requirements for the degree of \\ Master of Science in \\ Psychology
}

Amy Fiske, Ph.D., Chair
Barry Edelstein, Ph.D.
Julie Hicks Patrick, Ph.D.
Department of Psychology

Morgantown, West Virginia

2015

Keywords: perceived burdensomeness, older adults, younger adults

Copyright 2015 Julie Lutz 


\begin{abstract}
Perceived Burdensomeness in Older and Younger Adults: Evaluation of the Psychometric

Properties of the Interpersonal Needs Questionnaire
\end{abstract}

Julie Lutz

Perceived burdensomeness is a major risk factor in the Interpersonal Theory of Suicide, and may be particularly relevant in the older population, in which suicide rates are relatively high.

However, there is currently only one widely-used measure of perceived burdensomeness, and there is currently little information on the validity of this measure for older adults. The aims were to 1) evaluate measurement invariance of the INQ-15 Perceived Burdensomeness subscale across younger and older adult age groups, and 2) evaluate the construct validity of the Perceived Burdensomeness subscale in younger and older adult age groups by comparing nomological networks in both age groups. Nested multi-group confirmatory factor analyses (CFA) were used to address measurement invariance, whereas Fisher's $r$-to- $z$ transformations were used to compare correlations between perceived burdensomeness and other constructs in younger and older samples. The results of the measurement invariance analysis generally supported invariance, but signals of differences in fit in older adults were present. Correlations between perceived burdensomeness and other constructs were mostly similar. However, the INQ-15 Perceived Burdensomeness subscale exhibited a significantly lower correlation with depressive symptoms in older adults compared to younger adults. This study suggests that there may be some conceptual or measurement differences in perceived burdensomeness between younger and older adults. 


\section{TABLE OF CONTENTS}

Introduction 1

$\begin{array}{ll}\text { Perceived burdensomeness and suicide } & 2\end{array}$

The Interpersonal Needs Questionnaire (INQ) 3

$\begin{array}{ll}\text { Variables related to perceived burdensomeness } & 7\end{array}$

$\begin{array}{ll}\text { Statement of the problem and hypotheses } & 15\end{array}$

$\begin{array}{ll}\text { Method } & 17\end{array}$

$\begin{array}{ll}\text { Participants and procedures } & 17\end{array}$

$\begin{array}{ll}\text { Measures } & 19\end{array}$

$\begin{array}{ll}\text { Analyses } & 23\end{array}$

$\begin{array}{ll}\text { Results } & 26\end{array}$

$\begin{array}{lr}\text { Sample characteristics } & 26\end{array}$

$\begin{array}{ll}\text { Aim 1: Measurement invariance } & 27\end{array}$

$\begin{array}{ll}\text { Aim 2: Construct validity } & 27\end{array}$

$\begin{array}{ll}\text { Discussion } & 29\end{array}$

$\begin{array}{ll}\text { References } & 40\end{array}$

$\begin{array}{ll}\text { Tables } & 50\end{array}$

$\begin{array}{ll}\text { Figures } & 59\end{array}$

$\begin{array}{ll}\text { Appendices } & 61\end{array}$ 
Perceived Burdensomeness in Older and Younger Adults: Evaluation of the Psychometric Properties of the Interpersonal Needs Questionnaire

Whereas most attention and research on suicide is focused on risk factors related to the tragedy of death by suicide in adolescents and young adults, suicide in older adults is also a major concern in the United States and around the globe. While the national suicide rate in 2013 was 13 people out of 100,000, 16.1 out of 100,000 older adults age 65 and over died by suicide in the same year. Within this age group, rates increased by age, with a rate of 18.6 out of every 100,000 for those age 85 and over (Drapeau \& McIntosh, 2015). In addition, research has shown that older adults' suicidal acts are exponentially more likely to be fatal than younger adults' (Friedmann \& Kohn, 2008). These distressing numbers point to an urgent need for an understanding of the risk factors for suicide in older adults.

Many theories on the causes and antecedents of suicide have been generated. One fairly recent theory that has garnered much attention and been researched among many populations is Thomas Joiner, Jr.'s interpersonal theory of suicide (Joiner, 2005; Van Orden et al., 2010). The interpersonal theory (also called the interpersonal-psychological theory) posits that there are two factors, thwarted belongingness and perceived burdensomeness, that lead to a desire for suicide, and one additional factor, acquired capability to enact lethal self-harm behavior, that leads to greater lethality in suicide attempts or completed suicide. Thwarted belongingness refers to lack of social connectedness, isolation, and loneliness. Perceived burdensomeness refers to a belief that one is a burden on others, and at the most extreme extent, feeling as if one's loved ones would be better off if one were dead (Joiner, 2005). The construct of perceived burdensomeness has been further explained in detail as including two dimensions - beliefs that one is a liability toward loved ones and self-hatred cognitions (Van Orden et al., 2010). The current study is 
focused on this concept of perceived burdensomeness, its measurement, its relation to other psychosocial variables, and its relation to age.

\section{Perceived burdensomeness and suicide}

Since Joiner's (2005) theory was first published, many studies have found that perceived burdensomeness is related to suicidal ideation, as well as suicide fatality. In a comparison of suicide notes written by individuals who attempted suicide and who completed suicide, perceived burdensomeness was found to be a factor related to death by suicide or more lethal methods used in attempts (Joiner, Pettit, Walker, Voelz, \& Cruz, 2002). Among adult outpatients, higher level of perceived burdensomeness has been shown to be significantly related to suicidal ideation and suicide attempts, above the effects of depressive symptoms and hopelessness (Van Orden, Lynam, Hollar, \& Joiner, 2006). In a study on the entirety of the interpersonal theory, a main effect of perceived burdensomeness and an interaction effect with thwarted belongingness were found to be related to suicidal ideation among college students, indicating that the extent of suicidal ideation was amplified when both thwarted belongingness and perceived burdensomeness were at high levels (Van Orden, Witte, Gordon, Bender, \& Joiner, 2008). Another study with a community sample also found that perceived burdensomeness was correlated with suicidal ideation (Christensen, Batterham, Soubelet, \& Mackinnon, 2013). A review of the literature on clinical samples has led to the conclusion that there is a definite relation between perceived burdensomeness and suicidal behaviors and that there is some support for perceived burdensomeness serving as a moderator or mediator between established risk factors, such as depression, and suicidal behavior (Hill \& Pettit, 2014). Most of the research reviewed was cross-sectional.

Some studies have also specifically examined the relation between perceived 
burdensomeness and suicide in older adults. Perceived burdensomeness has been found to mediate the relation between depressive symptoms and suicidal ideation among older adults (Jahn, Cukrowicz, Linton, \& Prabhu, 2011), and has been shown to be a risk factor for suicidal ideation beyond the effects of other risk factors such as depressive symptoms, health, and hopelessness (Cukrowicz, Cheavens, Van Orden, Ragain, \& Cook, 2011). However, Christensen, Batterham, Soubelet, and Mackinnon (2013) found that the variables of the interpersonal model, as well as hopelessness, together accounted for less variance in suicidal ideation in older adults than in younger and middle-aged adults (though these were still significant correlates). This may point to a discrepancy in the mechanism by which the interpersonal theory influences suicidal ideation, attempts, and completion in older adults versus younger age groups. Further, Van Orden and colleagues (2006) found that burdensomeness is correlated with age, such that older individuals feel as if they are more of a burden on others. The participants in this study, however, only ranged up to age 62, so there was no information on this effect in an elderly sample over the age of 65 .

\section{The Interpersonal Needs Questionnaire (INQ)}

The Interpersonal Needs Questionnaire (INQ) was developed by Joiner and his colleagues to measure levels of thwarted belongingness and perceived burdensomeness (Van Orden et al., 2008; Van Orden, Cukrowicz, Witte, \& Joiner, 2012). The questionnaire consists of two subscales, one for thwarted belongingness and one for perceived burdensomeness. There are several forms of the INQ that have been used in previous research, varying in the number of items included. The items in all versions come from an original pool of 25 items (Van Orden et al., 2012). In general, the various forms of the INQ have been found to have adequate to strong psychometric support for their use. A 12-item version (INQ-12), with five items measuring 
thwarted belongingness and seven items measuring perceived burdensomeness, has been found to have high levels of internal consistency. More specifically, the Perceived Burdensomeness subscale has yielded alpha coefficients ranging from .89 to .93 (Cukrowicz et al., 2011; Freedenthal, Lamis, Osman, Kahlo, \& Gutierrez, 2011; Van Orden et al., 2008). Additionally, an 18-item version (INQ-18) has been constructed with 10 items in the Perceived Burdensomeness subscale. Alpha coefficients of .75 to .91 have been found for the Perceived Burdensomeness subscale of this version (Marty, Segal, Coolidge, \& Klebe, 2012; Nsamenang, Webb, Cukrowicz, \& Hirsch, 2013). Finally, a 15-item version (INQ-15) has been constructed that consists of nine thwarted belongingness items and six perceived burdensomeness items (Van Orden et al., 2012). In a sample of older adults, the Perceived Burdensomeness subscale of this version obtained an alpha coefficient of .74 (Cukrowicz, Jahn, Graham, Poindexter, \& Williams, 2013).

Evidence has supported varying degrees of validity of the different versions of the INQ in samples of young adults and adult clinical patients. In a study using samples of undergraduates and adult outpatient clients, concurrent validity has been supported through significant correlations between the Perceived Burdensomeness subscale of the INQ-12 and risk for suicide (Van Orden et al., 2008). Freedenthal and colleagues (2011) found, in a sample of undergraduate students, that factor analysis, as well as analyses of convergent and discriminant validity, supported use of the INQ-12 in general. However, some items that were meant for the Perceived Burdensomeness subscale did not load very strongly onto that factor in the factor analysis. This led the researchers to suggest making adjustments to the poorly-loaded items. Van Orden and colleagues (2012) used exploratory factor analyses in samples of undergraduate students with the 25 original INQ items to determine which 15 items strongly and exclusively 
loaded onto a perceived burdensomeness factor and a thwarted belongingness factor. They continued with confirmatory factor analyses in various samples (undergraduate students, adult outpatient clients, and older adults [see below]) to further support the construct validity of the INQ-15 by testing that the two subscales measured distinct constructs. Indicators showed acceptable fit for both the undergraduate and adult outpatient samples, though results were equivocal for older adults. A comparison of convergent and divergent validity in younger and older adults in this study is discussed below.

There have been only two studies on the psychometric properties of the INQ in older adults. Marty and colleagues (2012) examined properties of the INQ-18 in community-dwelling older adults, using factor analysis to confirm that the same two subscales, for perceived burdensomeness and thwarted belongingness, and factor structure were retained for the older adult sample. Some criterion validity analyses presented mixed results. The research showed that the Perceived Burdensomeness subscale correlated with variables such as self-esteem and loss of worth, as expected, but that it also correlated more strongly than the Thwarted Belongingness subscale with variables such as loneliness and reciprocal care, which were theorized to be more closely related to the construct of thwarted belongingness. In this sample, the Perceived Burdensomeness subscale did not seem to discriminate from thwarted belongingness as well as expected. This result may have been due to the convergent and discriminant measures selected to represent each construct, or to a true lack of discrimination between the Thwarted Belongingness and Perceived Burdensomeness subscales in the older population. This study did not directly compare older adults to younger adults on the INQ. Van Orden and colleagues' (2012) study of the INQ-15 (see discussion of this study above) incorporated comparisons of the measure between younger and older adults. This study 
included an analysis of measurement invariance between samples of younger and older adults, as well as a comparison of the convergent and discriminant validity between the INQ and other measures in both groups. The measurement invariance analysis, conducted using multi-group confirmatory factor analysis, indicated that the INQ-15 had equivalent factor structure in younger and older adults. The results provided some support for the conclusion that the INQ-15 items loaded equivalently onto the latent variables for both younger and older adults. However, the authors warned that the results should be viewed cautiously because one fit index indicated equivocal fit for the model in which item loadings were constrained to be equivalent across age groups. They suggested continued research on invariance across younger and older adults.

Van Orden and colleagues (2012) also examined convergent and discriminant validity of the INQ-15 in younger adults and older adults using structural equation modeling. In the sample of younger adults, perceived burdensomeness correlated significantly with autonomy, responsibility to family, and self-competence, as expected. It also significantly correlated with self liking, which had been hypothesized as a belongingness-related variable. However, it did not significantly correlate with any of the other measures that were expected to correlate with thwarted belongingness. In the sample of older adults, the Perceived Burdensomeness subscale correlated significantly with social worth and death ideation, but not with responsibility to family. Discrimination from thwarted belongingness was supported by lack of correlation with measures expected to be related to belongingness. A drawback of these analyses is that the nomological networks in each age group were not compared directly to each other to examine whether they were significantly similar or different (i.e. a different pattern of correlations for younger adults than for older adults). Also, the only validation measure for the Perceived Burdensomeness subscale that was used in both age groups was responsibility to family. 
While the two studies described above have made much progress in supporting the use of the INQ in older adults, there are some psychometric areas that have not been examined fully yet. A direct comparison between the nomological networks of the INQ in younger and older adults would have implications in both measurement and the theoretical sphere. By examining whether or not the convergent and discriminant relations between the INQ Perceived Burdensomeness subscale and other measures are significantly similar or different, one can determine whether the subscale is measuring the same latent construct in younger and older adults. From a broader point of view, these analyses may indicate whether younger and older adults experience perceived burdensomeness in the same manner.

\section{Variables related to perceived burdensomeness}

Depression. Many studies have demonstrated a relation between depressive symptoms and suicidal ideation or completion (for example: Turvey et al., 2002; Van Orden et al., 2006). Data collected in Finland over the course of treatment for suicidal ideation in older adults revealed that decreased symptoms of depression predicted decreased suicidal ideation (Sokero et al., 2006). As a common risk factor for suicide, depression has been included in various studies on the interpersonal theory of suicide, revealing how depression relates with the constructs of the theory, including perceived burdensomeness. Research on the relation between perceived burdensomeness and suicidal ideation that used depressive symptoms as an additional predictor of ideation revealed that, while both depressive symptoms and perceived burdensomeness acted as statistically significant predictors of ideation, perceived burdensomeness accounted for more variation in ideation above and beyond that accounted for by depressive symptoms (Van Orden et al., 2006). Another study performing similar analyses found a comparable result - in a multiple regression analysis, perceived burdensomeness again accounted for a significant amount 
of the variance in ideation, above that accounted for by depressive symptoms and other risk factors (Cukrowicz et al., 2011). Jahn and colleagues (2011) found that perceived burdensomeness in fact operated as a mediator of the relation between depressive symptoms and suicidal ideation. Kleiman, Liu, and Riskind (2014) found in a short prospective study of the interpersonal variables, depressive symptoms, and suicide that higher depressive symptoms were associated with higher perceived burdensomeness and thwarted belongingness, and to suicidal ideation. The results from these studies suggest that perceived burdensomeness operates as a significant risk factor for suicide separately from, but closely linked with, depression.

Additional research evidence supports the association between perceived burdensomeness and depression. A study examining which mental disorders predict the different facets of the interpersonal theory of suicide found that depressive disorders predict both perceived burdensomeness and thwarted belongingness (Silva, Ribeiro, \& Joiner, 2015). Studies comparing the relations of thwarted belongingness and perceived burdensomeness with other variables have indicated that perceived burdensomeness is more strongly correlated with depressive symptoms than is thwarted belongingness (Freedenthal et al., 2011; Marty et al., 2012). Correlations between measures of perceived burdensomeness and depressive symptoms have ranged from .24 to .71 in samples of younger adults (Freedenthal et al., 2011; Van Orden et al., 2006; 2008) and from .57 to .82 in samples of older adults (Cukrowicz et al., 2011; Jahn et al., 2011; Marty et al., 2012). Due to differences in sample characteristics and the measures used in each of these studies, comparisons cannot realistically be made between these correlations in younger and older adults. However, it is evident that depressive symptoms are moderately- to strongly-correlated with perceived burdensomeness, but that they are distinct constructs and each has a unique relation with suicidality. 
Hopelessness. Like depression, hopelessness has been shown to be a significant risk factor for desire for death or suicide in populations of diverse ethnicities, ages, and health statuses. Hopelessness as measured by the Beck Hopelessness Scale (see description below in method) has been found to be a predictor for suicidal ideation in older adults (Hill, Gallagher, Thompson, \& Ishida, 1988; Neufeld \& O’Rourke, 2009). A study by Hirsch, Visser, Chang, and Jeglic (2012) demonstrated that hopelessness was a moderator of the relation between depressive symptoms and suicidal behavior, with a smaller relation between depressive symptoms and suicidal behavior when hopelessness was low, in an ethnically diverse sample of young adults. Rodin and colleagues (2009) found that, in a sample of individuals with metastatic cancer, hopelessness and depressive symptoms significantly moderated the relations between other psychosocial risk factors (such as self-esteem, attachment, and spiritual well-being) and desire for a hastened death. In a study using information from caregivers of patients with amyotrophic lateral sclerosis (ALS, or Lou Gherig's disease), the patients' level of hopelessness at first interview was a predictor of discussing wanting assisted suicide at a later time (Ganzini, Silveira, \& Johnston, 2002). Additionally, the same study showed that individuals who discussed wanting assisted suicide felt more distress about being a burden on others.

Kleiman, Law, and Anestis (2013) integrated the interpersonal theory of suicide and the hopelessness theory of suicide put forth by Abramson and colleagues (1998), which states that individuals with a negative cognitive style (who attribute negative events to global, unchanging causes and tend to expect more negative future consequences of events) are more vulnerable to depression and suicidal ideation. The integrated theory proposes that a general negative cognitive style exhibits itself before the more specific attributions of thwarted belongingness and perceived burdensomeness are made to certain negative events. While negative cognitive style is 
the distal factor for suicide, thwarted belongingness and perceived burdensomeness are the more proximal factors. This would imply that negative cognitive style or hopelessness would be highly related to these factors. Kleiman and colleagues (2013) found in a sample of college students that perceived burdensomeness correlated more highly with negative cognitive style than did thwarted belongingness, though both correlations were significant. Also, the authors tested perceived burdensomeness and thwarted belongingness as mediators between negative cognitive style and suicidal ideation using a path model. The path from perceived burdensomeness to suicidal ideation was significant, while the path between thwarted belongingness and suicidal ideation was not. A model with perceived burdensomeness as the mediator between negative cognitive style and suicidal ideation was supported, while thwarted belongingness only mediated between negative cognitive style and suicidal ideation when perceived burdensomeness was taken out of the model.

An additional recent study, also with college students, found a significant negative association between trait hope and perceived burdensomeness after controlling for depressive symptoms (Anestis, Moberg, \& Arnau, 2014). Interestingly, this study found larger relations between trait hope and thwarted belongingness than between trait hope and perceived burdensomeness, which contradicts the findings of Kleiman and colleagues (2013).

Research such as the study described above, as well as multiple findings of strong correlations between hopelessness and perceived burdensomeness, suggest that these two variables interact in some way to affect suicidality, and that they are fairly closely related. Correlations between hopelessness and perceived burdensomeness have ranged from .20 to .53 in younger adults (Freedenthal et al., 2011; Van Orden et al., 2006) and from .44 to .60 in older adults (Cukrowicz et al., 2013; Jahn et al., 2011; Marty et al., 2012). One would expect to find a 
moderate to strong correlation between measures of hopelessness and perceived burdensomeness in further studies.

Autonomy. Beck (1983) has proposed that a cognitive style that reflects a high value placed on autonomy leads to higher risk for depression. This cognitive style has been operationalized as an individual's tendency to focus excessively on perfectionism, control over events, accomplishment of goals, and independence from others (Beck, 1983; Robins, Bagby, Rector, Lynch, \& Kennedy, 1997). Research has also shown that aspects of value placed on autonomy are related to suicidal behaviors in ways that appear to differ between younger and older adults. Value placed on autonomy, measured with the Autonomy scale of the Personal Style Inventory (Robins et al., 1997), as well as its subscales of Need for Control, Perfectionism, and Defensive Separation, correlate positively with suicidal behaviors in young adults, and the three factors have been shown to account for about $12 \%$ of the variance in suicidal behavior (O’Riley \& Fiske, 2012). However, in the same study, only Need for Control was significantly positively correlated with suicidal behaviors in older adults, and the three subscales accounted for approximately $9 \%$ of the variance in suicidal behaviors. These results, however, are challenged by another study that found that the relation between scores on the three subscales and suicidal behavior did not differ from the relation between total Autonomy scale scores and suicidal behavior in a sample of older adults (Bamonti, Price, \& Fiske, 2013).

A related construct that has also been proposed to be associated with affective outcomes is the extent to which an individual's need for autonomy is satisfied, conceptualized as satisfaction of the need for self-regulation or intrinsic motivation in performing behaviors (Deci \& Ryan, 2000). While the satisfaction of autonomy needs is a somewhat different concept from the value placed on autonomy, it is closely related. One could hypothesize that an individual 
who places a high value on autonomy, having an excessive need for control, perfectionism, and independence, would be least likely to feel as if their autonomy needs are being met, and therefore be low on autonomy need satisfaction. There has been little research so far comparing or relating both conceptualizations of autonomy.

Research that aimed to integrate the construct of autonomy need satisfaction and the interpersonal theory of suicide demonstrated that the relation between lower satisfaction of autonomy needs and suicidal ideation was an indirect one, with perceived burdensomeness and thwarted belongingness interceding (Hill \& Pettit, 2013). Additionally, this study showed that when depressive symptoms were added to the model, perceived burdensomeness retained a significant association with suicidal ideation, but thwarted belongingness did not. Therefore, one may conceptualize perceived burdensomeness as a mediator between lower satisfaction of autonomy needs and suicidal ideation. Autonomy need satisfaction and perceived burdensomeness were correlated moderately (Hill \& Pettit, 2013).

The focus of the proposed study is on the value placed on autonomy, as a cognitive style focusing on excessive need for control, perfectionism, and separation. Drawing from the results of the studies discussed above, it would be reasonable to expect that higher levels on this variable may be moderately positively correlated with perceived burdensomeness. Also, the results of the study by O'Riley and Fiske (2012), though focused on suicidal behavior rather than perceived burdensomeness itself, indicate that differences in the relation between value placed on autonomy and perceived burdensomeness depending on age group ought to be further explored.

Norm of reciprocity. The personal norm of reciprocity is an internalization of a social norm, referring to the extent to which one internalizes the belief that one should behave well 
toward those who have behaved well toward oneself (i.e. reward them) and that one should behave poorly toward those who have behaved poorly toward oneself (i.e. punish them; Perugini, Gallucci, Presaghi, \& Ercolani, 2003). In essence, the norm of reciprocity may be conceptualized as the extent to which one internalizes a belief that interactions should be equitable - if one individual does something for the other, the other individual does something in return. For the purpose of this study, we focus on the norm of positive reciprocity, or the concept of rewarding others who behave well toward oneself.

From this perspective, the extent to which one endorses positive reciprocity may affect one's perceptions of being a burden on others. A study examining the relation between the extent of equity in a caregiver-patient relationship, as perceived by patients, and self-perceived burden (a construct essentially identical with that of perceived burdensomeness, formulated through research on chronic or terminal illness and caregiving), showed that perceived inequity in the caregiver-patient relationship was moderately correlated with self-perceived burden (McPherson, Wilson, Chyurlia, \& Leclerc, 2010). Specifically, patients who reported that they were over-benefiting from the relationship (i.e. their caregivers did more for them than they did for their caregivers) had significantly higher levels of self-perceived burden. Expanding on the implications of these findings, it may be true that internalization of the norm of reciprocity is related to perceived burdensomeness. In other words, for the individual who would score higher on the personal norm of positive reciprocity, the balance of his or her relationships would be more salient, and an imbalance in which he or she over-benefited would lead to a higher level of perceived burdensomeness.

Another study showed differing effects of emotional support balance, or equivalence of emotional support received and given in relationships with family and friends, on life satisfaction 
between age groups (Li, Fok, \& Fung, 2011). Younger adults exhibited a quadratic trend, with higher levels of life satisfaction when they reported balanced support in their friendships and lower levels of life satisfaction when they either under-benefited or over-benefited from the friendships. Older adults, however, exhibited a linear trend, with the lowest levels of life satisfaction when they under-benefited from friendships, but the highest levels of life satisfaction when they over-benefited. This study indicates that the relation between balance or reciprocity in relationships and positive or negative subjective outcomes (life satisfaction in this study) may follow different patterns in younger and older adults. This may suggest that the relation between reciprocity and perceived burdensomeness may also alter depending on age group.

Control strategies. Heckhausen's model of optimization in primary and secondary control (OPS model) in the Motivational Theory of Lifespan Development puts forward a proposed pattern of changes in control strategies throughout the lifespan (Heckhausen, 1997; Heckhausen, Wrosch, \& Schulz, 2010). Heckhausen categorized coping into four categories: selective primary control, compensatory primary control, selective secondary control, and compensatory secondary control. For the purpose of this research, I have focused on the use of compensatory primary control strategies. Compensatory primary control refers to an individual's use of external resources to accomplish a goal after their own internal resources have been insufficient to accomplish the goal (Heckhausen, 1997; Heckhausen et al., 2010). These resources may include requesting help from others, using new or unusual procedures to accomplish the goal, using technological aids, and so on. Heckhausen posits that as adults age, they face more obstacles to achieving goals, and must adjust or alter their use of control strategies. The theory states that older adults will continue to use compensatory primary control strategies for as long as possible, until they must alternate to using compensatory secondary 
control strategies (i.e. avoiding negative experiences due to failure in achieving goals). This may include disengaging from goals).

Fiske, Bamonti, Nadorff, Petts, and Sperry (2013) examined the relation between the control strategies in the motivation theory and the outcomes of depressive symptoms and suicidal ideation in older adults with limitations due to health problems and found that endorsement of compensatory primary control strategies was negatively associated with depressive symptoms and with suicidal ideation. Expanding on Heckhausen's theory and the research by Fiske and colleagues, I put forward a hypothesis that an individual's willingness to seek help (a compensatory primary control strategy) may be protective against perceived burdensomeness and suicidal ideation. An individual who views asking others for help as a legitimate strategy for coping that allows him or her to continue to achieve some of his or her goals may not view the help they receive from others as negatively, or as such a large burden on others. Further, this relation between compensatory primary control and perceived burdensomeness may be more salient for older adults, who are more likely to need compensatory control strategies. This particular relationship has not been addressed through research at this point in time.

\section{Statement of the problem and hypotheses}

The rate of suicide in older adults is a significant concern in the United States, but the psychosocial factors contributing to these high rates of suicide have not been as thoroughly examined as those for younger adults. At the current time, one of the predominant models explaining suicide risk is the interpersonal theory put forth by Joiner (2005). In this theory, thwarted belongingness and perceived burdensomeness are stated to be the major contributors to a desire for death and subsequent risk for suicide. As research has shown that perceived burdensomeness is a particularly significant factor for older adults, it is crucial that this construct 
and those related to it are understood in an older adult population. An important first step in this process is to validly measure perceived burdensomeness. Evidence has already begun to accumulate to support the use of the perceived burdensomeness subscale of the Interpersonal Needs Questionnaire in older adults. By expanding on this research on the INQ subscale, we may demonstrate whether it measures the same basic latent construct in younger adults as in older adults, as well as gaining new insight into possible latent differences in the actual construct of perceived burdensomeness between younger and older adults.

The aims and hypotheses of this study are as follows:

Aim 1. Evaluate measurement invariance of the Interpersonal Needs Questionnaire Perceived Burdensomeness subscale across younger and older adult age groups.

Hypothesis 1. Measurement of perceived burdensomeness, using the INQ-15 subscale, will be invariant between younger and older adults.

Aim 2. Evaluate the construct validity of the Interpersonal Needs Questionnaire Perceived Burdensomeness subscale in younger and older adult age groups by comparing nomological networks in both age groups.

Hypothesis 2. The Perceived Burdensomeness subscale of the Interpersonal Needs Questionnaire will be positively correlated with suicidal behaviors in both younger and older adults.

Hypothesis 3. The Perceived Burdensomeness subscale will be positively correlated with depressive symptoms and hopelessness. In addition, the correlations of Perceived Burdensomeness with depressive symptoms and hopelessness will be stronger than the correlation between the Perceived Burdensomeness subscale and suicidal behaviors, as suggested by the more proximal relation with depression and desire to die compared to suicide attempts in 
the interpersonal theory.

Hypothesis 4. The Perceived Burdensomeness subscale will be positively correlated with value placed on autonomy in general, but this correlation will be somewhat stronger in younger adults than in older adults, as suggested by the age differences in the relation between autonomy and suicidal behavior found by O'Riley and Fiske (2012).

Hypothesis 5. The Perceived Burdensomeness subscale will be positively correlated with endorsement of a personal norm of positive reciprocity, but this correlation may be somewhat stronger in younger adults than in older adults, as suggested by the relation between reciprocity or relationship balance and other subjective outcomes such as life satisfaction (Li et al., 2011).

Hypothesis 6. The Perceived Burdensomeness subscale will be negatively correlated with compensatory primary control (specifically, help-seeking). This correlation will be somewhat stronger in older adults than in younger adults, as suggested by Heckhausen's (1997) OPS model.

\section{Method}

\section{Participants and procedures}

Sample 1. Secondary data from participants age 60 years and above were collected through participation in another, more extensive study. Participants are community-dwelling older adults recruited from senior centers, health fairs, posters, listervs, and existing lists of participants from previous research who indicated that they were willing to be contacted for future studies. All participants signed informed consent, participated in the experimental procedure of the other study, and then completed a questionnaire packet including some of the measures utilized in this study. The Montreal Cognitive Assessment (Nasreddine et al., 2005) was also administered, and 6 participants who scored below 20 points, indicating possible 
cognitive impairment, were excluded from the analyses, for a total of 67 participants included in the analyses. All participants received a gift card worth fifteen dollars (\$15).

Sample 2. An additional secondary sample of older adults over the age of 64 from the United States were recruited through Amazon’s Mechanical Turk (mTurk), an online marketplace for the coordination of workers to complete tasks, which has been used to collect questionnaire/survey data for behavioral research (Buhrmester, Kwang, \& Gosling, 2011; Mason \& Suri, 2012; Paolacci \& Chandler, 2014). Individuals participated in questionnaire research for reimbursement, which in this study was $\$ 0.50$. When participants chose to complete the survey online, they were first presented with an informed consent page. Then they were asked about their birth year, which was used to screen for individuals over the age of 64. Participants then went on to complete the questionnaires. At the end of the survey, participants were asked for their age in years. This age was compared to the year of birth for a second round of screening, to eliminate any invalid data. Four hundred thirty-six older adults filled out the survey online. Of these, 116 were kept as valid (completed the surveys in an appropriate duration of time). Finally, to ensure validity of the data, participants were removed for apparent inconsistent responding, such as selecting one response option for all items on a measure that included reverse-scored items or indicating non-matching birth years and ages. The final sample consisted of 75 participants.

Sample 3. A sample of younger adults, age 18 to 30, from the United States were recruited through MTurk and completed the study questionnaires online. Participants received \$0.25 for their participation. Participants were first presented with an informed consent page. After giving consent, participants were asked their year of birth and screened for age eligibility for the study. Those whose year of birth was consistent with being between the ages of 18 and 
30 years completed the questionnaires listed below, as well as demographic information (age, sex, race/ethnicity, socioeconomic status (type of hometown, highest level of education for self and parents, household income), and marital status. Five hundred and four individuals began the survey online. Participants who did not indicate their age at the end of the survey were eliminated from analyses, leaving 475 participants. Further data validation involved the following steps: 1) excluding data from participants whose year of birth indicated at the beginning of the survey did not match the age given at the end ( $n=19) ; 2)$ retaining only participants whose ages were between 18 and 30 years (excluded $n=14$ ); and 3) excluding participants who did not pass the validity items throughout the survey $(n=59)$. As a final validity check, participants who responded on one response option in longer questionnaires, even on items that were reverse-scored, were eliminated from data analysis $(n=5)$. The final sample consisted of 378 participants.

Use of the secondary data samples and collection of data in younger adults were approved by the West Virginia University Institutional Review Board.

\section{Measures}

Interpersonal Needs Questionnaire-15 (INQ-15). The INQ-15 was developed from an original set of 25 items measuring thwarted belongingness and perceived burdensomeness (Van Orden et al., 2012). It consists of two subscales: nine items on the Thwarted Belongingness subscale and six items on the Perceived Burdensomeness subscale. Responses are on a Likerttype scale from " 1 " (Not at all true) to "7" (Very true for me). Responses are summed, with total scores ranging from 6 to 42 . For the purpose of this research, only the Perceived Burdensomeness subscale was used. For all six items of the subscale, see Appendix A. For reliability and validity information, see the introduction (under "The Interpersonal Needs 
Questionnaire (INQ)." This questionnaire was collected in all samples used in this study. In the current samples, the INQ-15 Perceived Burdensomeness subscale yielded Cronbach's alpha coefficients of .84 in Sample 1, .94 in Sample 2, and .96 in Sample 3.

Center for Epidemiological Studies Depression Scale (CES-D). The CES-D was constructed as a brief measure to assess depressive symptoms in the general population. It consists of 20 items, with four response options, numbered 0 to 3: "Rarely or none of the time (less than 1 day)," "Some or a little of the time (1-2 days)," "Occasionally or a moderate amount of time (3-4 days)," and "Most or all of the time (5-7 days)" (Radloff, 1977). Four items are reverse-scored, and responses are summed for a total score ranging from 0 to 60 . For the full CES-D, see Appendix B. Reliability of the CES-D has been supported, with alphas ranging from .80 to .90 (Lewinsohn, Seeley, Roberts, \& Allen, 1997; Radloff, 1977). Several studies have also supported validity of the CES-D for use in populations of all ages (e.g. Beekman et al., 1997; Hertzog, Alstine, Usala, Hultsch, \& Dixon, 1990; Lewinsohn et al., 1997; Radloff, 1977). This scale was collected in Samples 1 and 3. In this study, the CES-D yielded Cronbach's alpha coefficients of .88 in Sample 1 and .93 in Sample 3.

Personal Style Inventory-Revised (PSI-II). The Personal Style Inventory was created to measure sociotropy and autonomy (specifically, a cognitive style placing high value on autonomy). In this research, only the Autonomy subscale was used. The PSI-II was drafted from the original set of PSI items, and the Autonomy subscale contains 24 items (Robins et al., 1994). Responses are on a 6-point Likert-type scale from "Strongly disagree" (1) to "Strongly agree." (6) Responses are summed for a total score ranging from 24 to 144 . For the full Autonomy subscale of the PSI-II, see Appendix C. Reliability of the PSI-II is supported by alphas of .83 to .86 , and a test-retest reliability coefficient of .70 (Robins et al., 1994; Robins et al., 1997). 
Robins and colleagues (1994) have also demonstrated support for criterion, convergent, and discriminant validity. In samples of undergraduates and outpatient adults, slight trends were found for gender, indicating that men score higher on value placed on autonomy (Robins et al., 1994; 1997). This inventory was collected in Samples 1 and 3. In this study, the PSI-II Autonomy subscale yielded Cronbach's alpha coefficients of .93 in Sample 1 and .90 in Sample 3.

\section{2-Item Personal Norm of Reciprocity (PNR). The Personal Norm of Reciprocity} questionnaire was designed with three subscales to measure positive reciprocity, negative reciprocity, and beliefs in reciprocity (or the extent to which one internalizes the norm of reciprocity; Perugini et al., 2003). While the original PNR contained nine items in each subscale, for a total of 27 , a shortened version has been created with four items in each subscale, for a total of 12 (Mateljkowski, McCarthy, \& Draine, 2011). Response options fall on a sevenpoint Likert-type scale, ranging from "Strongly disagree" to "Strongly agree." Responses on the items within each subscale are averaged for a score ranging from 1 to 7 . The Positive Reciprocity subscale of the shortened questionnaire exhibited adequate internal consistency $(\alpha=$ .70; Matejkowski et al., 2011). There was some evidence for convergent and discriminant validity for the Positive Reciprocity subscale (Matejkowski et al., 2011). This study, however, used a very small sample in comparison to most studies regarding the psychometrics of measures. For the full positive reciprocity subscale of the PNR, see Appendix D. This measure was collected in Samples 1 and 3. The PNR-12 was not administered to the first 13 pilot participants in Sample 1. In this study, the PNR Positive Reciprocity subscale yielded a Cronbach's alpha that was lower than expected in Sample $1(\alpha=.55)$, but yielded an adequate alpha of .79 in Sample 3. 
Optimization in Primary and Secondary Control scale (OPS). The Optimization in Primary and Secondary Control scale (OPS) was designed to measure control strategies as posited in Heckhausen's (1997) developmental theory of regulation of control (Heckhausen, Schultz, \& Wrosch, 1998). This questionnaire consists of multiple scales measuring selective primary and secondary control, compensatory primary and secondary control, and optimization (Heckhausen et al., 1998). For the purpose of this research, the help-seeking subfactor of the Compensatory Primary Control (CPC) subscale was used. This subfactor consists of four items with responses on a Likert-type scale ranging from "1" (never true) to "5" (almost always true; Heckhausen et al., 1998). Responses are summed for a total score ranging from 4 to 20 . For the full help-seeking subfactor of the Compensatory Primary Control subscale of the OPS, see Appendix E. Measurement invariance by age has been supported for the OPS (Heckhausen et al., 1998). Though there has not been much research on the psychometric properties of the scale, it has been modified and used in many contexts, including visual disabilities and eating behaviors (Brennan-Ing, Boerner, Horowitz, \& Reinhardt, 2013; deSouza, Mussap, \& Cummins, 2010; Schilling et al., 2013). The four-item help-seeking subfactor has produced an alpha of .87 (Fiske, Bamonti, Nadorff, Petts, \& Sperry, 2013). This measure was collected in all samples in this study. In this study, the OPS Help-Seeking subscale yielded Cronbach's alpha coefficients of .78 in Sample 1, .92 in Sample 2, and .90 in Sample 3.

Suicidal Behaviors Questionnaire-Revised (SBQ-R). The Suicidal Behaviors Questionnaire-Revised is a 4-item measure designed to assess an individual's current risk for suicidal behavior, based on past suicidal behavior (Osman et al., 2001). Each item has a different response scale. The first item asks about any past suicidal ideation or attempts, the second item asks about ideation in the past year, the third item asks whether the individual ever 
told another person about suicidal intent, and the fourth item asks how likely it is that the individual will attempt suicide "someday." Responses to the items are summed for a total score ranging from 3 to 18 . To see the full SBQ-R and response options, see Appendix F. There is support for the utility of the SBQ-R in helping to detect risk for suicide, using either the total score or the score on the first item (Osman et al., 2001). This measure was collected in Samples 2 and 3. In this study, the SBQ-R yielded Cronbach's alpha coefficients of .72 in Sample 2 and .80 in Sample 3 .

Beck Hopelessness Scale (BHS). The Beck Hopelessness Scale is a 20-item scale, with true-false responses, designed to measure hopelessness, or negative attitudes about the future (Beck, Weissman, Lester, \& Trexler, 1974). Some items are reverse-scored. Scores on the items are summed for a total ranging from 0 to 20, with higher scores indicating greater hopelessness. The scale has exhibited good internal consistency, with alphas ranging from .81 to .93 (Beck et al., 1974; Cukrowicz et al., 2011; Freedenthal et al., 2011). Many studies have supported the BHS's validity in suicide-related research in adults of all ages (for example: Cukrowicz et al., 2011). The BHS is copyrighted, and therefore the full version is not included in this document. This measure was collected in Samples 2 and 3. In this study, the BHS yielded Cronbach's alpha coefficients of .93 in Sample 2 and .92 in Sample 3.

\section{Analyses}

Aim 1: Measurement invariance. As a partial replication of Van Orden et al.’s (2012) work comparing the factor structure of the INQ-15 for older and younger adults, multiple-group confirmatory factor analyses (CFA) were used to test for measurement invariance of the INQ-15 Perceived Burdensomeness subscale between younger and older adults. Three models were tested, using increasing constraints. The first model constrained both age groups to the same 
basic factor structure. In this case, only the perceived burdensomeness subscale was analyzed. Therefore, all items were constrained to load onto a single factor. The second model also constrained both age groups to equivalent factor loadings. The final model added the constraint that the intercepts must be equivalent for both groups. The goodness of fit of each model was tested, as well as the extent to which goodness of fit decreased as each constraint was added, to determine whether the measure is invariant between age groups. To assess the goodness of fit of each model, the chi square $\left(\chi^{2}\right)$ values were examined, with nonsignificance indicating good fit. However, the chi square statistic is sensitive to sample size, distribution, and other assumptions, and therefore is not always the best indicator of goodness of fit in this type of analysis (Bentler, 1995). A rule of thumb applied to the chi square posits that a ratio of the chi square value to the degrees of freedom should be less than 2 (Tabachnick \& Fidell, 2007). However, the root mean square error of approximation (RMSEA) and comparative fit index (CFI) were also used. An RMSEA below .06 indicates good fit, while a value of greater than .08 indicates poor fit, and a CFI greater than 95 indicates good fit (Browne \& Cudeck, 1993; Hu \& Bentler, 1999). To assess the decrease in goodness of fit between nested models, the difference in the chi square between each consecutive model $\left(\chi_{\text {diff }}^{2}\right)$ was calculated and examined for significance (Vandenberg \& Lance, 2000). The change in CFI ( $\Delta$ CFI) for consecutive models provided an additional index of change in fit, with a difference greater than -.01 indicating that the null hypothesis (invariance) ought to be suspected (if the value lies between -.01 and -.02) or rejected (if greater than -.02; Cheung \& Rensvold, 2002; Vandenberg \& Lance, 2000).

Aim 2: Construct validity. The hypotheses of Aim 2 of the proposed study relate to comparisons of the relations between the INQ Perceived Burdensomeness subscale and other measures in older and younger adults. Total scores on all measures with more than 4 items and 
fewer than $15 \%$ of items missing were prorated by summing completed items, dividing this sum by the number of completed items, and then multiplying by the number of items on the measure. Using this procedure, there was minimal missing data in the final analyses (as indicated by sample sizes shown in Tables 1 and 2. Pearson correlations were conducted between the INQ Perceived Burdensomeness subscale and each of the other scales independently in each age group (younger adults and older adults). For the correlation between the OPS scale and INQ in older adults, Samples 1 and 2 (older adults) were combined (see results and discussion for information on similarity of these samples). In Sample 1, correlations between INQ perceived burdensomeness and the CES-D, PSI-II Autonomy subscale, and PNR Positive Reciprocity subscale were conducted. In Sample 2, correlations between INQ Perceived Burdensomeness and the SBQ-R and BHS were conducted. In Sample 3, all the above listed correlations were conducted.

Using Fisher's r-to-z transformation (Fisher, 1915; Meng, Rosenthal, \& Rubin, 1992), the correlations between each measure and the INQ in younger and older adults were compared to determine whether the correlations statistically significantly $(\alpha<.05)$ differed by age group. The Fisher's r-to-z transformation has been used previously for similar research questions (for example, see Freedenthal et al., 2011).

Power analyses for these comparisons were conducted using G*Power (Faul, Erdfelder, Lang, \& Buchner, 2007) for a two-tailed test of two independent Pearson r's, inputting alpha and power $(80 \%)$ criteria and sample sizes, and calculating the effect size that would be detectable under these conditions. For analyses performed comparing Sample 1 correlations with Sample 3 correlations, a moderate-high effect size of approximately $q=.38$ could be detected. For analyses performed comparing Sample 2 correlations with Sample 3 correlations, a moderate- 
high effect size of $q=.36$ could be detected. For the OPS analysis comparing the correlation in combined Samples 1 and 2 with the Sample 3 correlation, a small-moderate effect size of $q=.28$ could be detected. The effect size $\mathrm{q}$ is calculated based on the difference between the $\mathrm{z}$ transformations of the correlations. This is the first study to compare correlations between groups regarding perceived burdensomeness, so there is not a precedent for determining what effect size can be expected in these comparisons. As the first study to examine this area, a study powered for a moderate effect size is appropriate. At this size, the study could detect any moderate to large differences between age groups, and could indicate if further research must be done in the future to detect more subtle differences, based on signals detected in these analyses.

\section{Results}

\section{Sample characteristics}

See Table 1 for full information on sample age, gender, race/ethnicity, and level of education. The age of Sample 1 ranged from 60 to 93 years, Sample 2 ranged from 64 to 86 years, and Sample 3 ranged from 18 to 30 years. All samples were majority White/Caucasian, though the samples collected through MTurk (samples 2 and 3) contained somewhat more diversity. The greater proportion of White participants in Sample 1 is reflective of the West Virginia community, whereas the greater diversity in the MTurk samples is reflective of the overall greater diversity of the U.S. MTurk worker pool. The education level of all samples was relatively high. The majority of Sample 1 had a 4-year college degree or advanced degree, and all participants had at least completed their GED or high school diploma. In Sample 2, the majority of participants had at least some college or had completed a college degree. The majority of Sample 3 had completed some college or had completed a college degree.

Mean differences on all measures by sample and age group are shown in Table 2. Older 
adults had lower CES-D scores, lower PSI-II autonomy scores, lower PNR positive reciprocity scores, and lower SBQ-R scores than younger adults.

\section{Aim 1: Measurement invariance}

See Table 3 for the results of the analysis of measurement invariance. A multi-group confirmatory factor analysis (CFA) requiring equal form (i.e., single-factor structure) for both older and younger adults exhibited adequate fit in relation to CFI (.946). However, RMSEA was well above .08. Figures 1 and 2 show the multi-group model for younger and older adults, with standardized estimates from the equal-form model, and Table 4 shows all unstandardized estimates. When the item factor loadings were constrained to be equal in the younger and older samples, the fit of the model did not significantly decrease, as evidenced by a non-significant change in the chi-square value, as well as a decrease of less than .01 in the CFI. These results support the hypothesis that measurement of perceived burdensomeness using this INQ-15 subscale is invariant between younger and older adults. When equal intercepts were added as a restraint in the third model, the significant chi square indicated a significant decrease in fit, whereas the small $(<.01)$ decrease in CFI did not.

Due to the disagreement between fit indices for the first invariance model (equal singlefactor form for both younger and older adults), individual CFAs were conducted separately in both age groups to determine general fit of the single-factor model in each group. The results are shown at the bottom of Table 3. Whereas RMSEA fit indices were not adequate in either age group, fit as measured by the CFI was good in younger adults, but not in older adults.

\section{Aim 2: Construct validity}

Correlation matrices by older-adult sample (i.e. Samples 1 and 2) and by age group can be seen in Tables 5 and 6. Because not all questionnaires were included in each of the older- 
adult samples, some correlations could not be compared across these samples (e.g., it is not possible to compare correlations across the two older-adult samples). Before conducting correlation analyses, the assumptions of linearity and normality were assessed. The INQ Perceived Burdensomeness subscale was highly positively skewed and had high kurtosis, so correlations were run with both the original score, as well as a log transformation. The results of the correlations with the log transformation did not greatly differ, except for one correlation between the log-transformed INQ and OPS Help-seeking subscale in Sample 2, which became significant with a coefficient of -0.246 . The results of subsequent $r$-to- $z$ transformations and comparisons of correlations did not differ. Therefore, the results using the original scores are reported for ease of interpretation. The patterns of correlations between measures in Table 6 are relatively similar across age groups. The OPS Help-seeking subscale exhibits somewhat differing correlations with the SBQ-R and PNR Positive Reciprocity subscale across age groups, which may result from the small sizes of the correlations and difference in sample size between age groups.

The correlations between the INQ-15 and other measures by age group are highlighted in Table 7. The Perceived Burdensomeness subscale of the INQ-15 was correlated positively with the CES-D, SBQ-R, and BHS, and negatively with the Help-seeking subscale of the OPS, in both younger and older adults, as predicted in Hypotheses 2, 3, and 6. In younger adults, the PSI-II Autonomy subscale was also significantly positively correlated with the INQ Perceived Burdensomeness subscale, supporting Hypothesis 4 in this age group. Fisher's $r$-to- $z$ transformations revealed a significant difference in the correlation between the INQ Perceived Burdensomeness subscale and the CES-D between age groups, such that they were more highly correlated in younger adults than in older adults. No other correlations differed significantly, 
failing to support the age group differences suggested in Hypotheses 4, 5, and 6. These results are shown in Table 7.

\section{Discussion}

The purpose of this study was to determine how perceived burdensomeness, as measured by the INQ, functions in younger and older adults. The findings of the measurement invariance analyses provide mixed support for the validity of the INQ-15 Perceived Burdensomeness subscale in older adults, and the findings from the comparison of nomological networks between younger and older adults suggest that there are ways in which the construct of perceived burdensomeness may differ in older adults relative to younger age groups.

The multi-group CFA with younger and older adults revealed equivocal support for measurement invariance of the INQ-15 Perceived Burdensomeness subscale in younger and older adults. The models specifying equal forms and factor loadings exhibited adequate fit in regard to CFI. Fit was not similarly represented across different fit indices (e.g., RMSEA values well above the accepted upper limit, but acceptable CFI values). RMSEA may be more sensitive to low degrees of freedom (Kenny, Kaniskan, \& McCoach, 2015), and therefore the CFI may be considered the more valid fit index in this case. In comparison to Van Orden and colleagues' (2012) measurement invariance analysis of the full INQ-15, these results differed in greater support of measurement invariance via some fit indices, and in lesser support in others. However, the results of both studies were similar in that the indices of fit in both studies were somewhat ambiguous regarding invariance.

If the first model in the current analysis is accepted as adequately fitting the data, interpretation of the additional models constraining factor loadings to be equivalent and constraining intercepts to be equivalent reveals that there was not a significant loss of fit with 
equivalent factor loadings of the items, but that there is not support for invariance of the intercepts of the items, as shown by the significant increase in the chi-square statistic. This is consistent with Van Orden and colleagues' (2012) analysis, which supported invariance at the level of equivalent factor loadings, but was equivocal at the level of the intercepts.

Van Orden and colleagues (2012) used a criterion of .90 or greater for evaluating CFI values as having adequate fit. Even at this level, their CFA results were marginally indicative of equal form in respect to CFI, though fit as measured by the RMSEA was good. The current analysis revealed the opposite pattern, with higher CFI and inadequate RMSEA values. The disagreement in indices of fit for the model with equivalent single-factor structure could be suggestive of inadequate performance of some items or of differences in the construct of perceived burdensomeness between younger and older adults, or may simply be related to degrees of freedom. Individual CFA models run separately in younger and older adults revealed that CFI values indicated good fit of the single-factor structure in younger adults. Using the criteria established for this study, fit was not acceptable, per CFI, in older adults. However, if the .90 CFI criteria were used instead, fit would be considered acceptable in older adults. Therefore, the nature of the difference in fit between younger and older adults is still ambiguous, though there appears to be a signal that fit is poorer in older adults. Future research utilizing exploratory and confirmatory factor analyses of the Perceived Burdensomeness subscale items in older age groups could provide more insight into these differences. Though the current study provides interesting and valuable information regarding the INQ-15 and supports some of the findings by Van Orden and colleagues (2012), more evidence regarding the measurement variance or invariance of the INQ-15 by age should be garnered through analysis of larger samples, as the current samples of 142 older adults and 374 younger adults are smaller than Van 
Orden and colleagues' samples of 265 older adults and 456 undergraduate students..

An additional way in which the current study differed from the measurement invariance analysis conducted by Van Orden and colleagues (2012) was the focus on the single Perceived Burdensomeness subscale. Due to this focus, direct comparisons to Van Orden and colleagues' analysis are not possible, as overall fit of a model with two factors (one for perceived burdensomeness and one for thwarted belongingness) may differ from the fit of a single-factor model for one of the subscales. However, this separate analysis of the Perceived Burdensomeness subscale provides its own valuable information on the validity of measuring perceived burdensomeness as a separate construct using this measure in younger and older adults.

Mean differences indicating lower levels of depressive symptoms, value placed on autonomy, norm of positive reciprocity, and suicidal behavior in older adults, as shown in Table 2, are mainly consistent with past research and conceptual differences in age groups and with sample collection methods. Samples collected from Amazon MTurk report levels of clinical symptoms such as depression at rates similar to the general population (Shapiro, Chandler, \& Mueller, 2013). Also, data from these samples on variables such as personality factors are similar to samples collected in more traditional manners (e.g., university students; Buhrmester et al., 2011). The lower scores of older adults from the West Virginia community in comparison to younger adults on MTurk on the CES-D might be explained by the relatively high functioning of community-dwelling older adults and the relatively higher levels of clinical symptoms in MTurk samples compared to traditional samples. The mean difference in autonomy, as measured by the PSI-II, is consistent with previous findings, such that younger adults had higher mean scores than older adults (e.g., O’Riley \& Fiske, 2012). Research on the reasons for this difference could 
shed light on cohort or age differences in value placed on autonomy. The lower mean score on positive reciprocity in older adults may reflect a similar pattern as exhibited in the research by Li and colleagues (2011), where they found that older adults' life satisfaction was high even with imbalance in support if it represented disproportionate support provided to them in comparison to support they were able to offer. This result differed in their study from that for younger adults, where younger adults' life satisfaction was higher when relationships were equitable. Higher adherence to the norm of positive reciprocity would be consistent with higher satisfaction with equitable relationships in which one is able to "pay back" support, whereas lower adherence to the norm of positive reciprocity would be more consistent with satisfaction with a relationship in which one receives more than they can give back. Finally, the mean difference on the SBQ-R is consistent with research that has shown higher levels of suicidal ideation and attempts in young adults age 18 to 29 in comparison with older adults (Crosby, Han, Ortega, Parks, \& Gfroerer, 2011).

The correlations between the INQ-15 Perceived Burdensomeness subscale and other measures in older and younger adults, as seen in Table 7, provide insight into the nomological network of perceived burdensomeness in each age group. As stated in Hypothesis 2, the INQ-15 Perceived Burdensomeness subscale was positively correlated with suicidal behaviors, as measured by the SBQ-R, in both younger and older adults. Further, perceived burdensomeness was positively correlated with depressive symptoms and hopelessness in both age groups. Also as stated in Hypothesis 3, the correlations with the BHS were higher than those with the SBQ-R. However, interestingly, the correlation between CES-D depressive symptoms and perceived burdensomeness was much smaller in older adults than younger adults. This is a significant finding in regard to the conceptual understanding of perceived burdensomeness by age. 
Perceived burdensomeness has been found in several studies to serve as a factor that influences suicidality in close relation with depressive symptoms, but that explains additional variance in suicidal behavior over depressive symptoms, perhaps even serving as a mediator or moderator of the relation between depression and suicidal behavior (Cukrowicz et al., 2011; Jahn et al., 2011; Kleiman et al., 2014; Van Orden et al., 2006). The smaller correlation between perceived burdensomeness and depressive symptoms in older adults suggests that the previously-examined relations between these three variables must be further explored in terms of age differences. However, in a way this finding also supports the conclusions of the previous studies that perceived burdensomeness contributes something separately from depression to the explanation of suicidal behavior, because in these samples there was not a significant difference in the relation between perceived burdensomeness and suicidal behavior, as measured by the SBQ-R, despite the different correlations with depressive symptoms.

Hypothesis 4, which stated that value placed on autonomy would be positively correlated with perceived burdensomeness to a greater extent in younger adults than older adults, was not supported by the results of this study. There was a small but significant correlation between the two constructs in the younger sample, and there was no significant correlation found in the older sample. The $r$-to- $z$ comparison was not significant, but this may have been due to low power because of the small older-adult sample. Further examination of the relation between need for autonomy and perceived burdensomeness is necessary. Regardless of the significance of age differences, the finding of a significant correlation between these two constructs in younger adults provides novel information about perceived burdensomeness, as autonomy-related constructs have been examined in association with perceived burdensomeness only once in prior research (Hill \& Pettit, 2013), and value placed on autonomy has not been studied in association 
with perceived burdensomeness.

The PNR Positive subscale did not significantly correlate with the INQ-15 Perceived Burdensomeness subscale in either age group, therefore not providing support for Hypothesis 5. This may have been due to low power in the very small older-adult sample, though it was also not significantly correlated in the larger younger-adult sample. Also, both correlation coefficients were very small, therefore not providing a signal for a correlation that was hidden through lack of power. This finding differs from the findings of McPherson and colleagues (2010), who reported that stroke patients who perceived an inequity in relationships with their caregivers experienced higher self-perceived burden than those who did not report inequity. However, McPherson and colleagues focused on actual perceived inequity in a specific relationship (caregiver-patient), whereas the current study utilized a measure of overall internalization of the positive norm of reciprocity (i.e., the value placed on being able to keep relationships equitable by reciprocating if another does something for you) as it applies generally to all relationships. These somewhat different constructs may contribute to the difference in findings. This may be explained by a possible moderating factor that was not examined in this study-internalization of the norm of reciprocity may be related to perceived burdensomeness only in individuals who currently perceive inequity in relationships. Further research may examine whether the norm of reciprocity in cases where there is inequity in relationships may contribute to perceived burdensomeness.

Finally, help-seeking as measured in the OPS had small, but significant, negative correlations with perceived burdensomeness, as stated in Hypothesis 6, in both younger and older adults. There was not a significant difference in these correlations between age groups. These findings support the hypothesized link between willingness to seek help to accomplish 
goals and perceived burdensomeness, such that those who are more willing to seek help are less likely to then perceive that they are a burden on others. Future research should further explore the direction of the causal relation or whether there is a third variable involved. In other words, do those who see themselves as a burden on others then decide not to seek help, or does openness to seeking help protect against perceived burdensomeness? Are there general attitudes that influence both help seeking and perceived burdensomeness?

There are some limitations to this study. First, the use of secondary data sets for the older adult samples led to some limitations in sample size. Both samples have a fairly small sample size, and therefore there is power only to detect moderate to large effect sizes. However, this study still makes an important contribution to the literature on perceived burdensomeness and the INQ. As the first study to directly compare the nomological networks in each age group, detection (or lack of detection) of any moderate to large effect sizes is a crucial first step in either supporting or failing to support use of the INQ in all age groups, and in determining whether perceived burdensomeness is the same in older and younger adults. Even with the small sample size, a significant difference in the correlation between the INQ-15 Perceived Burdensomeness subscale and depressive symptoms as measured by the CES-D was detected. The signal of a difference in the correlation between value placed on autonomy and perceived burdensomeness also indicates an area for future research to examine.

Older adult samples were combined where possible for analyses to improve power. There were some differences between the two samples regarding diversity and mean scores on the INQ-15 Perceived Burdensomeness subscale. However, it was determined that, for the purpose of this study, combining samples was appropriate. Whereas Sample 1 included mainly white, well-educated older adults, in combination with Sample 2, the older adult sample was 
more diverse and was more closely matched to the younger sample. Though the two samples may represent somewhat different populations of older adults, combining them allowed for greater overall representation of older adults in the United States.

An additional limitation to this study, particularly Samples 2 and 3, is that the use of Amazon's mTurk for surveys and questionnaires is relatively new to social science research. Therefore, the advantages and disadvantages of this procedure for data collection are continuously being examined, and are not currently fully known. While advantages include the ability to recruit diverse samples from varying geographic areas and ease of data collection, one concern regards the validity of data in two aspects: 1) certainty that the individual does not misrepresent themselves regarding screening variables such as age, and 2) certainty that each individual's data is of high quality. In this study, a validity check was included in an attempt to sift out invalid data due to misrepresentation of age. Because Sample 2 was meant to include only older adults and Sample 3 was meant to include only younger adults, individuals were not only asked either their age or year of birth at the beginning of the survey, but also asked for the other indicator at the end. During data cleaning, the responses to these items were examined to determine if there were any discrepancies, and participants whose responses did not match were not included in the final sample. To address the second concern, data were examined for patterns to determine whether any individuals responded using one option in an entire questionnaire, despite items that were reversed or worded in the opposite direction. Overall, the data included in the analyses in this study are believed to be as valid as those that would be collected in any other study involving questionnaires and administered online. For a comprehensive discussion of the advantages and disadvantages of using mTurk to conduct research, see Mason and Suri (2011) and Paolacci and Chandler (2014). 
Another limitation to this study is a floor effect due to studying a clinical and low-rate variable, such as suicidal behavior, in a non-clinical sample. The INQ-15 Perceived Burdensomeness subscale and the SBQ-R, to a somewhat lower extent, were found to have high positive skew, with responses clustering at the lowest scores. Nonetheless, results were very similar when the INQ-15 Perceived Burdensomeness subscale was transformed to improve the distribution, suggesting that this skew was not detrimental to the accuracy of the statistical tests.

Finally, the use of a cross-sectional correlational design, which precludes any conclusions about cause-and-effect relations between the variables, is a limitation to this study. These same limitations have applied to other research in this area (see Freedenthal et al., 2011; Marty et al., 2012; and Van Orden et al., 2008) due to the greater difficulty, amount of resources, and ethical concerns related to recruiting samples of clinically suicidal participants or doing prospective research on suicide. A future research direction in this area would be to expand upon the findings obtained in the proposed study using clinical samples, larger sample sizes, and prospective study designs to determine the directions of the correlations revealed by the current study.

The results of this study point to several areas for further examination through future research. First, additional attempts at replication of measurement invariance analyses with large older- and younger-adult samples will be necessary to demonstrate stronger support for equivalence of the measure between these age groups. This study and that conducted by Van Orden and colleagues (2012) had mixed positive and ambiguous outcomes. In fact, it may be valuable to conduct exploratory factor analyses of all the original perceived burdensomeness items from the 25-item INQ in older adults specifically, as opposed to the previous undergraduate samples (Van Orden et al., 2012), to examine whether different sets of items may 
be retained in this age group.

Another important area for further research is the establishment of construct validity in younger and older adults through examination of the nomological network of perceived burdensomeness as measured in the INQ. In particular, this study found that there was a difference in how perceived burdensomeness related to depressive symptoms by age group. Exploration of how perceived burdensomeness relates to other constructs in different age groups goes hand-in-hand with the need for general exploration of factors related to perceived burdensomeness in all ages. Some of this was attempted in the current study, by examining how need for autonomy, internalization of the norm of positive reciprocity, and willingness to seek help were related to perceived burdensomeness. Whereas research has established quite well that perceived burdensomeness is associated with suicidal ideation and behavior, there has been less research on factors that contribute to perceived burdensomeness and that could be treated to reduce risk in this particular area.

The long-term goal that this study is designed to address is to gain an understanding of the factors related to suicidal ideation, behaviors, and death, and to use this information to implement interventions to prevent suicide. By getting an in-depth picture of the correlates of perceived burdensomeness by age group, the proposed research facilitates the targeting of perceived burdensomeness and related constructs as important areas for further research and possible development of interventions for suicide. This study demonstrates that there may be some conceptual or measurement differences in perceived burdensomeness between younger and older adults. Further research on these differences must be completed to determine whether it is truly appropriate to use the same measure of perceived burdensomeness in both age groups. Examining these age differences in perceived burdensomeness and its measurement is a crucial 
step in identifying important risk factors and interventions for suicide. 


\section{References}

Abramson, L.Y., Alloy, L.B., Hogan, M.E., Whitehouse, W.G., Cornette, M., Akhavan, S., \& Chiara, A. (1998). Suicidality and cognitive vulnerability to depression among college students: a prospective study. Journal of Adolescence, 21, 473-487.

Anestis, M.D., Moberg, F.B., \& Arnau, R.C. (2014). Hope and the interpersonal-psychological theory of suicidal behavior: Replication and extension of prior findings. Suicide and Life-Threatening Behavior, 44, 175-187. doi: 10.1111/sltb.12060

Armstrong, L., Wuthrich, V.M., Knight, A., \& Joiner, R. (2014). Worry and depression in the old and young: Differences and mediating factors. Behaviour Change, 31, 279-289. doi: 10.1017/bec.2014.21

Bamonti, P. M., Price, E. C., \& Fiske, A. (2013). Depressive symptoms and suicide risk in older adults: Autonomy as a moderator for men but not women. Suicide and Life-Threatening Behavior. Advance online publication. doi:10.1111/s1tb.12062

Beck, A.T., Epstein, N., \& Harrison, R. (1983). Cognitions, attitudes and personality dimensions in depression. British Journal of Cognitive Psychotherapy, 1, 1-16.

Beck, A.T., Weissman, A., Lester, D., \& Trexler, L. (1974). The measurement of pessimism: The hopelessness scale. Journal of Consulting and Clinical Psychology, 42, 861-865.

Beekman, A.T.F., Deeg, D.J.H., Van Limbeek, J., Braam, A.W., De Vries, M.Z., \& Van Tilburg, W. (1997). Criterion validity of the Center for Epidemiologic Studies Depression scale (CES-D): Results from a community-based sample of older subjects in the Netherlands. Psychological Medicine, 27, 231-235.

Bentler, P.M. (1995). EQS: Structural equations program manual. Encino, CA: Multivariate Software, Inc. 
Brennan-Ing, M., Boerner, K., Horowitz, A., \& Reinhardt, J. (2013). The vision-specific optimization in primary and secondary control (OPS) scale. European Journal of Ageing, 10, 345-352. doi: 10.1007/s10433-013-0278-4

Browne, M.W., \& Cudeck, R. (1993). Alternative ways of assessing model fit. In K.A. Bollen \& J.S. Long (Eds.), Testing structural equation models (pp. 136-162). Newsbury Park, CA: Sage.

Buhrmester, M., Kwang, T., \& Gosling, S.D. (2011). Amazon’s Mechanical Turk: A new source of inexpensive, yet high-quality, data? Perspectives on Psychological Science, 6, 3-5. doi: 10.1177/1745691610393980

Cheung, G.W. \& Rensvold, R.B. (2002). Evaluating goodness-of-fit indexes for testing measurement invariance. Structural Equation Modeling, 9, 233-255.

Christensen, H., Batterham, P.J., Soubelet, A., \& Mackinnon, A.J. (2013). A test of the Interpersonal Theory of Suicide in a large community-based cohort. Journal of Affective Disorders, 144, 225-234. doi: 10.1016/j.jad.2012.07.002

Crosby, A.E., Han, B., Ortega, L.A., Parks, S., \& Gfroerer, J. (21 October, 2011). Suicidal thoughts and behaviors among adults aged $\geq 18$ years - United States, 2008-2009. Centers for Disease Control and Prevention Morbidity and Mortality Weekly Report Surveillance Summaries, 60 (13), 1-22.

Cukrowicz, K.C., Cheavens, J.S., Van Orden, K.A., Ragain, R.M., \& Cook, R.L. (2011). Perceived burdensomeness and suicide ideation in older adults. Psychology and Aging, 26, 331-338. doi: 10.1037/a0021836

Cukrowicz, K.C., Jahn, D.R., Graham, R.D., Poindexter, E.K., \& Williams, R.B. (2013). Suicide risk in older adults: Evaluating models of risk and predicting excess zeros in a 
primary care sample. Journal of Abnormal Psychology, 122, 1021-1030. doi:

10.1037/a0034953

Deci, E.L., \& Ryan, R.M. (2000). The "what" and "why" of goal pursuits: Human needs and the self-determination of behavior. Psychological Inquiry, 11, 227-268.

DeSouza, M., Mussap, A.J., \& Cummins, R.A. (2010). Primary and secondary control over eating behaviors. Eating Behaviors, 11, 223-230. doi:10.1016/j.eatbeh.2010.05.002

Drapeau, C.W., \& McIntosh, J.L. (2015). USA suicide 2013: Official final data. Washington, DC: American Association of Suicidology.

Faul, F., Erdfelder, E., Lang, A.-G., \& Buchner, A. (2007). G*Power 3: A flexible statistical power analysis program for the social, behavioral, and biomedical sciences. Behavior Research Methods, 39, 175-191.

Fisher, R.A. (1915). Frequency distribution of the values of the correlation coefficient in samples from am indefinitely large population. Biometrika, 10, 507-521.

Fiske, A., Bamonti, P. M., Nadorff, M. R., Petts, R. A., \& Sperry, J. A. (2013). Control strategies and suicidal ideation in older primary care patients with functional limitations. International Journal of Psychiatry in Medicine, 46, 271-289. doi: 10.2190/PM.46.3.c

Freedenthal, S., Lamis, D.A., Osman, A., Kahlo, D., \& Gutierrez, P.M. (2011). Evaluation of the psychometric properties of the Interpersonal Needs Questionnaire-12 in samples of men and women. Journal of Clinical Psychology, 67, 609-623. doi: 10.1002/jclp.20782

Friedmann, H. \& Kohn, R. (2008). Mortality, or probability of death, from a suicidal act in the United States. Suicide and Life-Threatening Behavior, 38, 287-301. 
Ganzini, L., Silveira, M.J., \& Johnston, W.S. (2002). Predictors and correlated of interest in assisted suicide in the final month of life among ALS patients in Oregon and Washington. Journal of Pain and Symptom Management, 24, 312-317.

Heckhausen, J. (1997). Developmental regulation across adulthood: Primary and secondary control of age-related challenges. Developmental Psychology, 33, 176-187.

Heckhausen, J., Schulz, R., \& Wrosch, C. (1998). Developmental regulation in adulthood: Optimization in primary and secondary control - a multiscale questionnaire (OPS-Scales) [technical report]. Berlin, Germany: Max Planck Institute for Human Development.

Heckhausen, J., Wrosh, C., \& Schulz, R. (2010). A motivational theory of life-span development. Psychological Review, 117, 32-60. doi: 10.1037/a0017668

Hertzog, C., Van Alstine, J., Usala, P.D., Hultsch, D.F., \& Dixon, R. (1990). Measurement properties of the Center for Epidemiological Studies Depression Scale (CES-D) in older populations. Psychological Assessment, 2, 64-72.

Hill, R.M. \& Pettit, J.W. (2013). The role of autonomy needs in suicidal ideation: Integrating the interpersonal-psychological theory of suicide and self-determination theory. Archives of Suicide Research, 17, 288-301. doi: 10.1080/13811118.2013.777001

Hill, R.M., \& Pettit, J.W. (2014). Perceived burdensomeness and suicide-related behaviors in clinical samples: Current evidence and future directions. Journal of Clinical Psychology, 70, 631-643. doi: 10.1002/jclp.22071

Hill, R.D., Gallagher, D., Thompson, L.W., \& Ishida, T. (1988). Hopelessness as a measure of suicidal intent in the depressed elderly. Psychology and Aging, 3, 230-232. 
Hirsch, J.K., Visser, P.L., Chang, E.C., \& Jeglic, E.L. (2012). Race and ethnic differences in hope and hopelessness as moderators of the association between depressive symptoms and suicidal behavior. Journal of American College Health, 60, 115-125.

Hu, L. \& Bentler, P.M. (1999). Cutoff criteria for fit indexes in covariance structure analysis: Conventional criteria versus new alternatives. Structural Equation Modeling, 6, 1-55. doi: $10.1080 / 10705519909540118$

Jahn, D.R., Cukrowicz, K.C., Linton, K., \& Prabhu, F. (2011). The mediating effect of perceived burdensomeness on the relation between depressive symptoms and suicide ideation in a community sample of older adults. Aging \& Mental Health, 15, 214-220. doi: $10.1080 / 13607863.2010 .501064$

Joiner, T. (2005). Why People Die by Suicide. Cambridge, MA: Harvard University Press.

Joiner, T.E., Pettit, J.W., Walker, R.L., Voelz, Z.R., \& Cruz, J. (2002). Perceived burdensomeness and suicidality: Two studies on the suicide notes of those attempting and those completing suicide. Journal of Social and Clinical Psychology, 21, 531-545.

Kenny, D.A., Kaniskan, B., \& McCoach, D.B. (2015). The performance of RMSEA in models with small degrees of freedom. Sociological Methods \& Research, 44, 486-507. doi: $10.1177 / 0049124114543236$

Kleiman, E.M., Law, K.C., \& Anestis, M.D. (2013). Do theories of suicide play well together? Integrating components of the hopelessness and interpersonal psychological theories of suicide. Comprehensive Psychiatry. doi:10.1016/j.comppsych.2013.10.015

Kleiman, E.M., Liu, R.T., \& Riskind, J.H. (2014). Integrating the interpersonal psychological theory of suicide into the depression/suicidal ideation relationship: A short-term prospective study. Behavior Therapy, 45, 212-221. 
Lewinsohn, P.M., Seeley, J.R., Roberts, R.E., \& Allen, N.B. (1997). Center for Epidemiologic Studies Depression Scale (CES-D) as a screening instrument for depression among community-residing older adults. Psychology and Aging, 12, 277-287.

Li, T., Fok, H.K., \& Fung, H.H. (2011). Is reciprocity always beneficial? Age differences in the association between support balance and life satisfaction. Aging \& Mental Health, 15, 541-547. doi: 10.1080/13607863.2010.551340

Marty, M.A., Segal, D.L., Coolidge, F.L., \& Klebe, K.J. (2012). Analysis of the psychometric properties of the Interpersonal Needs Questionnaire (INQ) among community-dwelling older adults. Journal of Clinical Psychology, 68, 1008-1018. doi: 10.1002/jclp.21877

Mason, W. \& Suri, S. (2012). Conducting behavioral research on Amazon's Mechanical Turk. Behavior Research Methods, 44, 1-23. doi: 10.3758/s13428-011-0124-6

Matejkowski, J., McCarthy, K.S., \& Draine, J. (2011). The Personal Norm of Reciprocity among mental health service users: Conceptual development and measurement. Psychiatric Rehabilitation Journal, 34, 202-213. doi: 10.2975/34.3.2011.202.213

McPherson, C.J., Wilson, K.G., Chyurlia, L., \& Leclerc, C. (2010). The balance of give and take in caregiver-partner relationships: An examination of self-perceived burden, relationship equity, and quality of life from the perspective of care recipients following stroke. Rehabilitation Psychology, 55, 194-203. doi: 10.1037/a0019359

Meng, X., Rosenthal, R., \& Rubin, D.B. (1992). Comparing correlated correlation coefficients. Psychological Bulletin, 111, 172-175.

Nasreddine, Z.S., Phillips, N.A., Bédirian, V., Charbonneau, S., Whitehead, V., Collin, I., ... Chertkow, H. (2005). The Montreal Cognitive Assessment, MoCA: A brief screening 
tool for mild cognitive impairment. Journal of the American Geriatric Society, 53, 695699.

Neufeld, E. \& O’Rourke, N. (2009). Impulsivity and hopelessness as predictors of suiciderelated ideation among older adults. Canadian Journal of Psychiatry, 54, 684-692.

Nsamenang, S.A., Webb, J.R., Cukrowicz, K.C., \& Hirsch, J.K. (2013). Depressive symptoms and interpersonal needs as mediators of forgiveness and suicidal behavior among rural primary care patients. Journal of Affective Disorders, 149, 282-290. doi: 10.1016/j.jad.2013.01.042

O’Riley, A.A. \& Fiske, A. (2012). Emphasis on autonomy and propensity for suicidal behavior in younger and older adults. Suicide and Life-Threatening Behavior, 42, 394-404. doi: 10.1111/j.1943-278X.2012.00098.x

Osman, A., Bagge, C.L., Gutierrez, P.M., Konick, L.C., Kopper, B.A., \& Barrios, F.X. (2001). The Suicidal Behaviors Questionnaire-Revised (SBQ-R): Validation with clinical and nonclinical samples. Assessment, 8, 443-454. doi: 10.1177/107319110100800409

Paolacci, G., \& Chandler, J. (2014). Inside the turk: Understanding Mechanical Turk as a participant pool. Current Directions in Psychological Science, 23, 184-188. doi: $10.1177 / 0963721414531598$

Perugini, M., Gallucci, M., Presaghi, F., \& Ercolani, A.P. (2003). The Personal Norm of Reciprocity. European Journal of Personality, 17, 251-283. doi: 10.1002/per.474

Radloff, L.S. (1977). The CES-D Scale: A self-report depression scale for research in the general population. Applied Psychological Measurement, 1, 385-401. doi: $10.1177 / 014662167700100306$ 
Robins, C.J., Bagby, R.M., Rector, N.A., Lynch, T.R., \& Kennedy, S.H. (1997). Sociotropy, autonomy, and patterns of symptoms in patients with major depression: A comparison of dimensional and categorical approaches. Cognitive Therapy and Research, 21, 285-300.

Robins, C.J., Ladd, J., Welkowitz, J., Blaney, P.H., Diaz, R., \& Kutcher, G. (1994). The Personal Style Inventory: Preliminary validation studies of new measures of sociotropy and autonomy. Journal of Psychopathology and Behavioral Assessment, 16, 277-297.

Rodin, G., Lo, C., Mikulincer, M., Donner, A., Gagliese, L., \& Zimmermann, C. (2009). Pathways to distress: The multiple determinants of depression, hopelessness, and the desire for hastened death in metastatic cancer patients. Social Science \& Medicine, 68, 562-569. doi: 10.1016/j.socscimed.2008.10.037

Schilling, O.K., Wahl, H.W., Boerner, K., Reinhardt, J.P., Brennan-Ing, M., \& Horowitz, A. (2013). Change in psychological control in visual impaired older adults over 2 years: Role of functional ability and depressed mood. Journal of Gerontology Series B: Psychological Sciences and Social Sciences, 68, 750-761. doi: 10.1093/geronb/gbs118

Shapiro, D.N., Chandler, J., \& Mueller, P.A. (2013). Using Mechanical Turk to study clinical populations. Clinical Psychological Science, 1, 213-220. doi:

$10.1177 / 2167702612469015$

Silva, C., Ribeiro, J.D., \& Joiner, T.E. (2015). Mental disorders and thwarted belongingness, perceived burdensomeness, and acquired capability for suicide. Psychiatry Research, 226, 316-327. doi: 10.1016/j.psychres.2015.01.008

Sokero, P., Eerola, M., Rytsälä, H., Melartin, T., Leskelä, U., Lestelä-Mielonen, P., \& Isometsä, E. (2006). Decline in suicidal ideation among patients with MDD is preceded by decline 
in depression and hopelessness. Journal of Affective Disorders, 95, 95-102. doi: 10.1016/j.jad.2006.04.028

Tabachnick, B.G. \& Fidell, L.S. (2007). Using multivariate statistics (5 ${ }^{\text {th }}$ ed., p. 715). Boston, MA: Pearson/Allyn \& Bacon.

Turvey, C.L., Conwell, Y., Jones, M.P., Phillips, C., Simonsick, E., Pearson, J.L., \& Wallace, R. (2002). Risk factors for late-life suicide. American Journal of Geriatric Psychiatry, 10, $398-406$.

Vandenberg, R.J. \& Lance, C.E. (2000). Review and synthesis of the measurement invariance literature: Suggestions, practices, and recommendations for organizational research. Organizational Research Methods, 3, 4-70. doi: 10.1177/109442810031002

Van Orden, K.A., Cukrowicz, K.C., Witte, T.K., \& Joiner, T.E. (2012). Thwarted belongingness and perceived burdensomeness: Construct validity and psychometric properties of the Interpersonal Needs Questionnaire. Psychological Assessment, 24, 197 215. doi: $10.1037 / \mathrm{a} 0025358$

Van Orden, K.A., Lynam, M.E., Hollar, D., \& Joiner, T.E. (2006). Perceived burdensomeness as an indicator of suicidal symptoms. Cognitive Therapy and Research, 30, 457-467. doi: $10.1007 / \mathrm{s} 10608-006-9057-2$

Van Orden, K.A., Witte, T.K., Cukrowicz, K.C., Braithwaite, S.R., Selby, E.A., \& Joiner, T.E. (2010). The interpersonal theory of suicide. Psychological Review, 117, 575-600. doi: $10.1037 / \mathrm{a} 0018697$

Van Orden, K.A., Witte, T.K., Gordon, K.H., Bender, T.W., \& Joiner, T.E. (2008). Suicidal desire and the capability for suicide: Tests of the Interpersonal-Psychological Theory of 
Suicidal Behavior among adults. Journal of Consulting and Clinical Psychology, 76, 7283. doi: 10.1037/0022-006X.76.1.72 
Table 1

Sample Characteristics

\begin{tabular}{|c|c|c|c|c|c|c|c|c|}
\hline \multirow[b]{2}{*}{ Measure } & \multicolumn{2}{|c|}{ Sample 1} & \multicolumn{2}{|c|}{ Sample 2} & \multicolumn{2}{|c|}{ Older adults } & \multicolumn{2}{|c|}{ Sample 3 (Younger) } \\
\hline & $n$ & $\%$ & $n$ & $\%$ & $n$ & $\%$ & $n$ & $\%$ \\
\hline Age $(M, S D)$ & 69.70 & 8.10 & 68.53 & 3.71 & 69.08 & 6.19 & 25.01 & 3.30 \\
\hline \multicolumn{9}{|l|}{ Gender } \\
\hline Female & 38 & $56.7 \%$ & 56 & $74.7 \%$ & 94 & $66.2 \%$ & 236 & $62.4 \%$ \\
\hline Male & 29 & $43.3 \%$ & 19 & $25.3 \%$ & 48 & $33.8 \%$ & 142 & $37.6 \%$ \\
\hline \multicolumn{9}{|l|}{ Race/Ethnicity } \\
\hline White/Caucasian, not Hispanic & 64 & $97.0 \%$ & 65 & $86.7 \%$ & 129 & $91.5 \%$ & 275 & $72.8 \%$ \\
\hline Black or African American & 1 & $1.5 \%$ & 6 & $8.0 \%$ & 7 & $5.0 \%$ & 40 & $10.6 \%$ \\
\hline Hispanic or Latino/Latina & 0 & $0 \%$ & 0 & $0 \%$ & 0 & $0 \%$ & 21 & $5.6 \%$ \\
\hline Native American or Native Alaskan & 0 & $0 \%$ & 1 & $1.3 \%$ & 1 & $0.7 \%$ & 0 & $0 \%$ \\
\hline Asian or Pacific Islander & 1 & $1.5 \%$ & 0 & $0 \%$ & 1 & $0.7 \%$ & 33 & $8.7 \%$ \\
\hline Other or multi-racial & 0 & $0 \%$ & 3 & $4.0 \%$ & 3 & $2.1 \%$ & 9 & $2.4 \%$ \\
\hline
\end{tabular}

Education 


\begin{tabular}{|c|c|c|c|c|c|c|c|c|}
\hline Some high school & 0 & $0 \%$ & 3 & $4.0 \%$ & 3 & $2.2 \%$ & 4 & $1.1 \%$ \\
\hline GED & 4 & $6.3 \%$ & 2 & $2.7 \%$ & 6 & $4.3 \%$ & 7 & $1.9 \%$ \\
\hline High school diploma & 11 & $17.2 \%$ & 14 & $18.7 \%$ & 25 & $18.0 \%$ & 30 & $8.0 \%$ \\
\hline Some college & 9 & $14.1 \%$ & 16 & $21.3 \%$ & 25 & $18.0 \%$ & 139 & $36.9 \%$ \\
\hline 2-year college degree & 0 & $0 \%$ & 15 & $20.0 \%$ & 15 & $10.8 \%$ & 32 & $8.5 \%$ \\
\hline 4-year college degree & 20 & $31.3 \%$ & 17 & $22.7 \%$ & 37 & $26.6 \%$ & 137 & $36.3 \%$ \\
\hline Advanced degree & 20 & $31.3 \%$ & 8 & $10.7 \%$ & 28 & $20.1 \%$ & 28 & $7.4 \%$ \\
\hline
\end{tabular}


Table 2

Mean Age and Scores on Measures

\begin{tabular}{|c|c|c|c|c|c|c|c|c|c|c|c|c|c|}
\hline \multirow[b]{2}{*}{ Measures } & \multicolumn{3}{|c|}{ Sample 1} & \multicolumn{3}{|c|}{ Sample 2} & \multicolumn{3}{|c|}{ Older Adults } & \multicolumn{3}{|c|}{ Sample 3 (Younger) } & \multirow[b]{2}{*}{$t(d f)$} \\
\hline & $n$ & $M$ & $S D$ & $n$ & $M$ & $S D$ & $n$ & $M$ & $S D$ & $n$ & $M$ & $S D$ & \\
\hline INQ-15 PB & 67 & 7.16 & 3.57 & 75 & 12.47 & 8.08 & 142 & 9.96 & 6.88 & 374 & 10.49 & 7.43 & $0.73(514)$ \\
\hline CES-D & 67 & 10.17 & 8.58 & - & - & - & - & - & - & 378 & 17.58 & 12.25 & $6.06(119.65)^{* * *}$ \\
\hline PSI-II Aut & 67 & 72.90 & 18.99 & - & - & - & - & - & - & 377 & 85.73 & 17.79 & $5.38(442)^{* * *}$ \\
\hline PNR-12 Pos & 54 & 4.91 & 0.75 & - & - & - & - & - & - & 378 & 5.52 & 1.02 & $5.33(83.911)^{* * *}$ \\
\hline OPS HS & 67 & 14.54 & 2.79 & 75 & 14.04 & 3.63 & 142 & 14.27 & 3.26 & 378 & 13.75 & 3.41 & $1.59(518)$ \\
\hline SBQ-R & - & - & - & 75 & 5.07 & 2.69 & - & - & - & 378 & 6.08 & 3.29 & $2.88(122.31)^{* *}$ \\
\hline BHS & - & - & - & 75 & 5.62 & 5.52 & - & - & - & 377 & 5.42 & 5.39 & $0.29(450)$ \\
\hline
\end{tabular}

Note. Numbers under Older Adults represent means of combined Samples 1 and 2 where relevant; if blank, only one sample includes this measure and the means are listed under that sample. T-tests compare means in older and younger adult samples. Degrees of freedom that are not a whole number indicate that the test of equality of variances yielded a significant result, indicating unequal variances, and the Satterthwaite adjustment was used. INQ-15 PB = Perceived Burdensomeness subscale of the 15-item Interpersonal Needs Questionnaire; CES-D = Centers for Epidemiological Studies Depression questionnaire; PSI-II Aut = Autonomy subscale of the Personal Style Inventory-II; PNR-12 Pos = Positive Reciprocity subscale of the 12-item Personal Style Inventory; OPS HS = Help- 
Seeking subscale of the Optimization of Primary and Secondary Control scale; SBQ-R = Suicidal Behaviors Questionnaire-Revised; BHS $=$ Beck Hopelessness Scale

$* p<.05 ; * * p<.01 ; * * * p<.001$. 
Table 3

Multi-group Confirmatory Factor Analysis for Measurement Invariance

\begin{tabular}{lccccccc} 
Model & $\chi^{2}$ & $d f$ & $\Delta \chi^{2}$ & $\Delta d f$ & RMSEA & CFI & $\Delta$ CFI \\
\hline Equal form & $186.298^{* * *}$ & 18 & - & - & .134 & .946 & - \\
Equal factor loadings & $196.495 * * *$ & 23 & 10.197 & 5 & .121 & .944 & -.002 \\
Equal intercepts & $213.123 * * *$ & 29 & $16.628 *$ & 6 & .111 & .941 & -.003 \\
& & & & & & & \\
Younger adults $^{\mathrm{a}}$ & $112.762^{* * *}$ & 9 & - & - & .175 & .957 & - \\
Older adults $^{\mathrm{a}}$ & $73.435^{* * *}$ & 9 & - & - & .225 & .908 & - \\
\hline
\end{tabular}

Note. RMSEA = root mean square error of approximation; CFI = comparative fit index.

${ }^{\text {a }}$ Individual CFAs in each age group specifying a single-factor solution.

$* p<.05 ; * * p<.01 ; * * * p<.001$. 
Table 4

Unstandardized Estimates of Model Specifying Equal Form Between Younger and Older Adults Younger Adults Older Adults

INQ-15 PB Item

Est. SE Inter. Var. $\quad$ Est. SE Inter. Var.

\begin{tabular}{lcccccccc}
\hline "Better off" & 1.000 & - & 1.775 & .313 & 1.000 & - & 1.697 & .643 \\
"Happier without me" & 1.036 & .037 & 1.787 & .356 & .958 & .073 & 1.662 & .409 \\
"Burden on society" & 1.131 & .043 & 1.869 & .509 & .865 & .075 & 1.606 & .589 \\
"Death as relief" & .925 & .034 & 1.541 & .315 & .807 & .073 & 1.634 & .598 \\
"Rid of me" & .949 & .033 & 1.633 & .257 & .927 & .074 & 1.662 & .482 \\
"Makes things worse" & 1.045 & .045 & 1.883 & .670 & .904 & .071 & 1.704 & .416
\end{tabular}

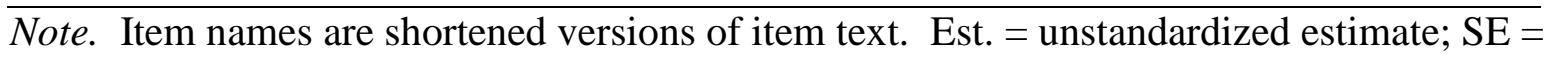
standard error of the estimate; Inter. = item intercept; Var. = item variance. See Appendix A for full text of the INQ-15 Perceived Burdensomeness measure. Only unstandardized estimates are shown here. See Figures 1 and 2 for standardized estimates. 
Table 5

Correlations by Sample of Older Adults

\begin{tabular}{lccccccc} 
& 1 & 2 & 3 & 4 & 5 & 6 & 7 \\
1. INQ-15 PB & -- & $.324 * *$ & .022 & .115 & .046 & - & - \\
\cline { 2 - 7 } 2. CES-D & - & -- & $.582^{* * *}$ & .116 & -.232 & - & - \\
3. PSI-II Aut & - & - & -- & -.050 & $-.345 * *$ & - & - \\
4. PNR-12 Pos & - & - & - & -- & -.052 & - & - \\
5. OPS HS & -.219 & - & - & - & -- & - & - \\
6. SBQ-R & $.436 * * *$ & - & - & - & .084 & -- & - \\
7. BHS & $.609 * * *$ & - & - & - & -.222 & $.333^{* *}$ & -
\end{tabular}

Note. Sample 1 correlations above the diagonal, Sample 2 correlations below the diagonal.

Missing correlations represent measures that were not collected in each respective sample.

$* p<.05 ; * * p<.01 ; * * * p<.001$. 
Table 6

Correlations by Age Group

\begin{tabular}{|c|c|c|c|c|c|c|c|}
\hline & 1 & 2 & 3 & 4 & 5 & 6 & 7 \\
\hline 1. INQ-15 PB & -- & $.659 * * *$ & $.252 * * *$ & -.072 & $-.228 * * *$ & $.468 * * *$ & $.661 * * *$ \\
\hline 2. CES-D & $.324 * *$ & -- & $.407 * * *$ & -.091 & $-.293 * * *$ & $.548 * * *$ & $.698 * * *$ \\
\hline 3. PSI-II Aut & .022 & $.582 * * *$ & -- & $-.112 *$ & $-.414 * * *$ & $.293 * * *$ & $.355^{* * *}$ \\
\hline 4. PNR-12 Pos & .115 & .116 & -.050 & -- & $.183 * * *$ & .041 & $-.137 * *$ \\
\hline 5. OPS HS & $-.170 *$ & -.232 & $-.345 * *$ & -.052 & -- & $-.199 * * *$ & $-.254 * * *$ \\
\hline 6. SBQ-R & $.436 * * *$ & - & - & - & .084 & -- & $.457 * * *$ \\
\hline 7. BHS & $.609 * * *$ & - & - & - & -.222 & $.333 * *$ & -- \\
\hline
\end{tabular}

Note. Younger adult correlations above the diagonal, older adult correlations below the diagonal. Missing correlations in the older adult sample represent measure combinations that did not occur in the same participants.

$* p<.05 ; * * p<.01 ; * * * p<.001$. 
Table 7

Fisher's r-to-z Comparisons of Correlations to INQ Perceived Burdensomeness by Age Group

Older adults Younger adults

\begin{tabular}{|c|c|c|c|c|c|c|c|}
\hline \multirow{2}{*}{ Measure } & & & & & \multirow[b]{2}{*}{$z_{\text {diff }}$} \\
\hline & $n$ & $r$ & $z$ & $n$ & $r$ & $z$ & \\
\hline CES-D & 67 & $.324 * *$ & .337 & 374 & $.659 * * *$ & .791 & $3.355^{* * *}$ \\
\hline PSI-II Aut & 67 & .022 & .022 & 373 & $.252 * * *$ & .258 & 1.744 \\
\hline PNR-12 Pos & 54 & .115 & .116 & 374 & -.072 & -.072 & -1.258 \\
\hline OPS HS & 142 & $-.170 *$ & -.172 & 374 & $-.228 * * *$ & -.233 & -0.611 \\
\hline SBQ-R & 75 & $.436 * * *$ & .467 & 374 & $.468 * * *$ & .507 & 0.311 \\
\hline BHS & 75 & $.609 * * *$ & .707 & 374 & $.661 * * *$ & .794 & 0.675 \\
\hline
\end{tabular}

Note. Correlations are to the INQ-15 Perceived Burdensomeness subscale. $z_{\text {diff }}=\left(z_{\text {younger }}-\right.$

$\left.z_{\text {older }}\right) / \sqrt{ }\left(1 /\left[n_{\text {younger }}-3\right]+1 /\left[n_{\text {older }}-3\right]\right)$

$* p<.05 ; * * p<.01 ; * * * p<.001$. 


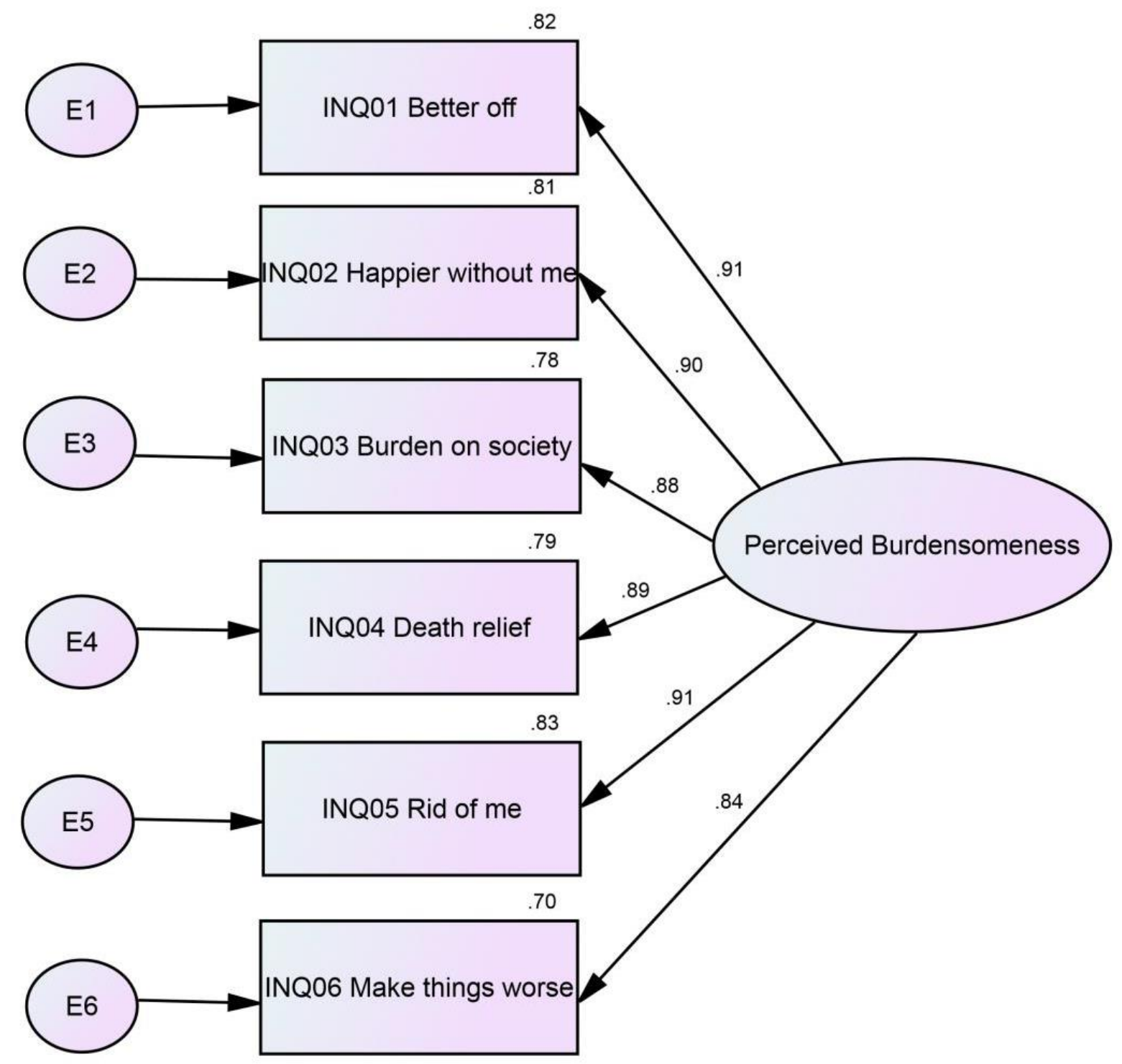

Figure 1. Multi-group confirmatory factor analytic model with younger adults constrained to single-factor structure. Figure shows standardized estimates. For unstandardized estimates, see Table 4. 


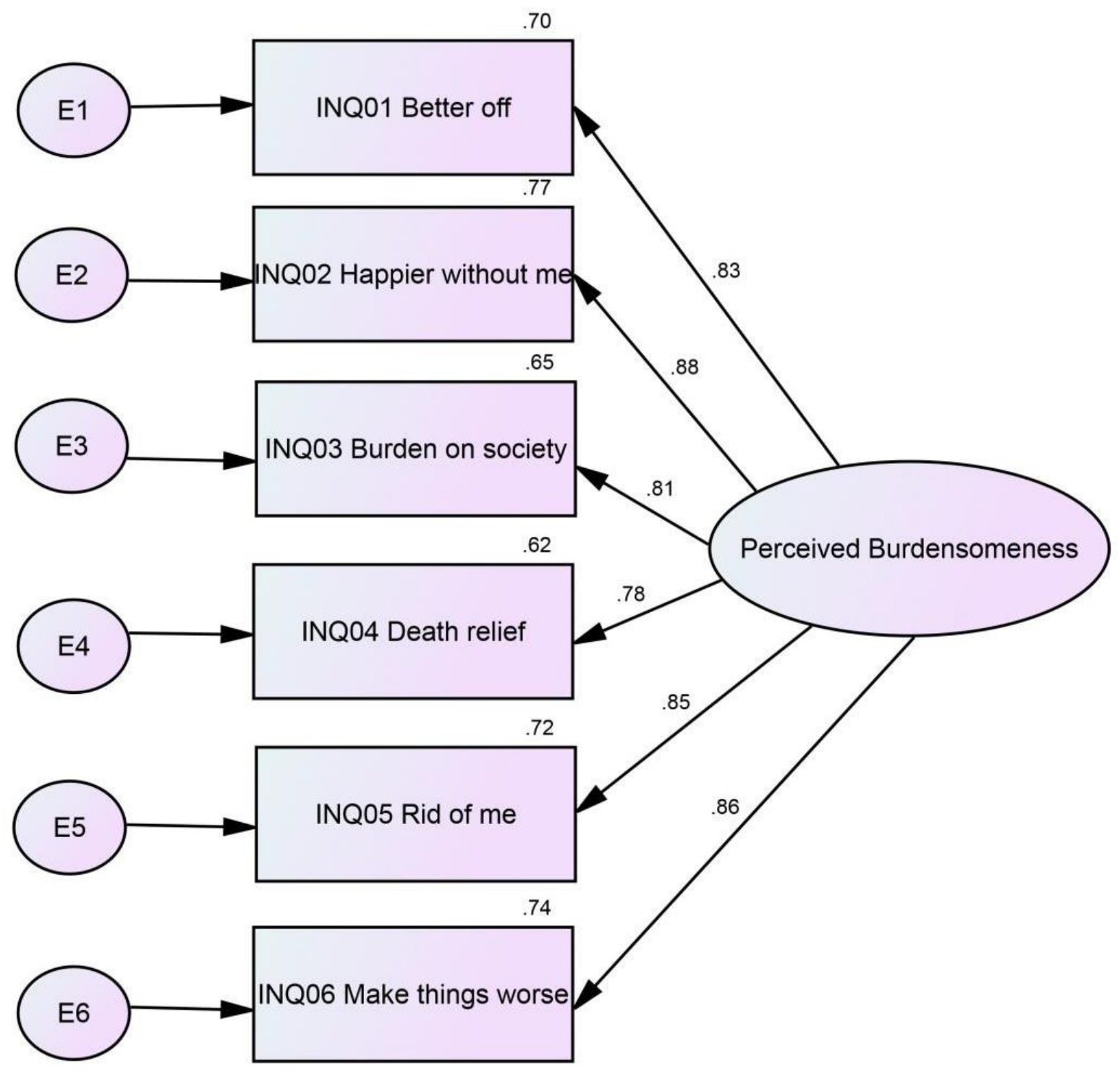

Figure 2. Multi-group confirmatory factor analytic model with older adults constrained to single-factor structure. Figure shows standardized estimates. For unstandardized estimates, see Table 4. 


\author{
Appendix A \\ Interpersonal Needs Questionnaire-15 \\ Perceived Burdensomeness subscale
}

The following questions ask you to think about yourself and other people. Please respond to each question by using your own current beliefs and experiences, NOT what you think is true in general, or what might be true for other people. Please base your responses on how you've been feeling recently. Use the rating scale to find the number that best matches how you feel and circle that number. There are no right or wrong answers: we are interested in what you think and feel.

1. These days, the people in my life would be better off if I were gone.

$\begin{array}{cccccc}1 & 2 & 3 & 5 & 6 & 7 \\ \text { Not at all true } & \text { Somewhat for me } & & \text { True for me } & \text { Very true for me }\end{array}$

2. These days, the people in my life would be happier without me.

$\begin{array}{cccccc}1 & 2 & 3 & 5 & 6 & 7 \\ \text { Not at all true } & \text { Somewhat for me } & & \text { True for me } & \text { Very true for me }\end{array}$

\title{
3. These days, I think I am a burden on society.
}

$\begin{array}{cccclc}1 & 2 & 3 & 5 & 6 & 7 \\ \text { Not at all true } & \text { Somewhat for me } & & \text { True for me } & \text { Very true for me }\end{array}$

4. These days, I think my death would be a relief to the people in my life.

$\begin{array}{cccclc}1 & 2 & 3 & 5 & 6 & 7 \\ \text { Not at all true } & \text { Somewhat for me } & & \text { True for me } & \text { Very true for me }\end{array}$

\section{These days, I think the people in my life wish they could be rid of me.}

$\begin{array}{cccclc}1 & 2 & 3 & 5 & 6 & 7 \\ \text { Not at all true } & \text { Somewhat for me } & & \text { True for me } & \text { Very true for me }\end{array}$

\section{These days, I think I make things worse for the people in my life.}

$\begin{array}{cccclc}1 & 2 & 3 & 5 & 6 & 7 \\ \text { Not at all true } & \text { Somewhat for me } & & \text { True for me } & \text { Very true for me }\end{array}$




\section{Appendix B}

Center for Epidemiological Studies Depression Scale

Below is a list of the ways you might have felt or behaved. Please check the boxes to tell me how often you have felt this way in the past week or so.

\begin{tabular}{|l|l|l|l|l|}
\hline DURING THE PAST WEEK: & $\begin{array}{l}\text { Rarely or } \\
\text { Not at All }\end{array}$ & $\begin{array}{l}\text { Some of } \\
\text { the Time }\end{array}$ & Occasionally & $\begin{array}{l}\text { Most of } \\
\text { the Time }\end{array}$ \\
\hline $\begin{array}{c}\text { 1. I was bothered by things that don't usually } \\
\text { bother me. }\end{array}$ & & & & \\
\hline $\begin{array}{c}\text { 2. I did not feel like eating, my appetite was } \\
\text { poor. }\end{array}$ & & & & \\
\hline $\begin{array}{c}\text { 3. I felt that I could not shake the blues even } \\
\text { with the help from my family and friends. }\end{array}$ & & & & \\
\hline $\begin{array}{c}\text { 4. I felt that I was just as good as other } \\
\text { people. }\end{array}$ & & & & \\
\hline $\begin{array}{c}\text { 5. I had trouble keeping my mind on what I } \\
\text { was doing. }\end{array}$ & & & & \\
\hline 6. I felt depressed. & & & & \\
\hline 7. I felt that everything I did was an effort. & & & \\
\hline 8. I felt hopeful about the future. & & & & \\
\hline 9. I thought my life had been a failure. & & & & \\
\hline 10. I felt fearful. & & & & \\
\hline 11. My sleep was restless. & & & & \\
\hline 12. I was happy. & & & & \\
\hline 13. I talked less than usual. & & & & \\
\hline 14. I felt lonely. & & & & \\
\hline 15. People were unfriendly. & & & & \\
\hline 16. I enjoyed life. & & & & \\
\hline 17. I had crying spells. & & & & \\
\hline 18. I felt sad. & & & & \\
\hline
\end{tabular}




\begin{tabular}{|l|l|l|l|l|}
\hline DURING THE PAST WEEK: & $\begin{array}{l}\text { Rarely or } \\
\text { Not at All }\end{array}$ & $\begin{array}{l}\text { Some of } \\
\text { the Time }\end{array}$ & Occasionally & $\begin{array}{l}\text { Most of } \\
\text { the Time }\end{array}$ \\
\hline 19. I felt that people dislike me. & & & & \\
\hline 20. I could not "get going". & & & & \\
\hline
\end{tabular}




\section{Appendix C}

\section{Personal Style Inventory-Revised}

\section{Autonomy subscale}

Here are a number of statements about personal characteristics. Please read each one carefully, and indicate whether you agree or disagree, and to what extent, by selecting the response.

\begin{tabular}{|c|c|c|c|c|c|c|}
\hline & $\begin{array}{l}\text { Strongly } \\
\text { Disagree }\end{array}$ & Disagree & $\begin{array}{l}\text { Slightly } \\
\text { Disagree }\end{array}$ & $\begin{array}{l}\text { Slightly } \\
\text { Agree }\end{array}$ & Agree & $\begin{array}{l}\text { Strongly } \\
\text { Agree }\end{array}$ \\
\hline $\begin{array}{l}\text { 1. I am easily bothered by } \\
\text { other people making } \\
\text { demands of me. }\end{array}$ & & & & & & \\
\hline $\begin{array}{l}\text { 2. In relationships, people } \\
\text { are often too demanding } \\
\text { of one another. }\end{array}$ & & & & & & \\
\hline $\begin{array}{l}\text { 3. It is hard for me to take } \\
\text { instructions from people } \\
\text { who have authority over } \\
\text { me. }\end{array}$ & & & & & & \\
\hline $\begin{array}{l}\text { 4. It is hard for me to } \\
\text { have someone dependent } \\
\text { on me. }\end{array}$ & & & & & & \\
\hline $\begin{array}{l}\text { 5. I resent it when people } \\
\text { try to direct my behavior } \\
\text { or activities. }\end{array}$ & & & & & & \\
\hline $\begin{array}{l}\text { 6. I am very upset when } \\
\text { other people or } \\
\text { circumstances interfere } \\
\text { with my plans. }\end{array}$ & & & & & & \\
\hline $\begin{array}{l}\text { 7. I become upset more } \\
\text { than most people I know } \\
\text { when limits are placed on } \\
\text { my personal } \\
\text { independence and } \\
\text { freedom. }\end{array}$ & & & & & & \\
\hline
\end{tabular}




\begin{tabular}{|c|c|c|c|c|c|c|}
\hline & $\begin{array}{l}\text { Strongly } \\
\text { Disagree }\end{array}$ & Disagree & $\begin{array}{l}\text { Slightly } \\
\text { Disagree }\end{array}$ & $\begin{array}{l}\text { Slightly } \\
\text { Agree }\end{array}$ & Agree & $\begin{array}{l}\text { Strongly } \\
\text { Agree }\end{array}$ \\
\hline $\begin{array}{l}\text { 8. I feel controlled when } \\
\text { others have a say in my } \\
\text { plans. }\end{array}$ & & & & & & \\
\hline $\begin{array}{l}\text { 9. I tend to keep other } \\
\text { people at a distance. }\end{array}$ & & & & & & \\
\hline $\begin{array}{l}\text { 10. I don't like relying on } \\
\text { others for help. }\end{array}$ & & & & & & \\
\hline $\begin{array}{l}\text { 11. When I'm feeling } \\
\text { blue, I don't like to be } \\
\text { offered sympathy. }\end{array}$ & & & & & & \\
\hline $\begin{array}{l}\text { 12. I don't like people to } \\
\text { invade my privacy. }\end{array}$ & & & & & & \\
\hline $\begin{array}{l}\text { 13. I often handle big } \\
\text { decisions without telling } \\
\text { anyone else about them. }\end{array}$ & & & & & & \\
\hline $\begin{array}{l}\text { 14. It is hard for me to } \\
\text { express admiration or } \\
\text { affection. }\end{array}$ & & & & & & \\
\hline $\begin{array}{l}15 . \text { It is difficult for me to } \\
\text { make a long-term } \\
\text { commitment to a } \\
\text { relationship. }\end{array}$ & & & & & & \\
\hline $\begin{array}{l}\text { 16. It is hard for me to } \\
\text { open up and talk about } \\
\text { my feelings and other } \\
\text { personal things. }\end{array}$ & & & & & & \\
\hline $\begin{array}{l}\text { 17. When making a big } \\
\text { decision, I usually feel } \\
\text { that advice from others is } \\
\text { intrusive. }\end{array}$ & & & & & & \\
\hline $\begin{array}{l}\text { 18. Personal questions } \\
\text { from others usually feel } \\
\text { like an invasion of my } \\
\text { privacy. }\end{array}$ & & & & & & \\
\hline
\end{tabular}




\begin{tabular}{|l|l|l|l|l|l|l|}
\hline & $\begin{array}{l}\text { Strongly } \\
\text { Disagree }\end{array}$ & Disagree & $\begin{array}{l}\text { Slightly } \\
\text { Disagree }\end{array}$ & $\begin{array}{l}\text { Slightly } \\
\text { Agree }\end{array}$ & Agree & $\begin{array}{l}\text { Strongly } \\
\text { Agree }\end{array}$ \\
\hline $\begin{array}{l}\text { 19. I rarely trust the } \\
\text { advice of others when } \\
\text { making a big decision. }\end{array}$ & & & & & \\
\hline $\begin{array}{l}\text { 20. I become upset when } \\
\text { others try to influence my } \\
\text { thinking on a problem. }\end{array}$ & & & & & & \\
\hline $\begin{array}{l}\text { 21. It bothers me when I } \\
\text { feel that I am only } \\
\text { average and ordinary. }\end{array}$ & & & & & & \\
\hline $\begin{array}{l}\text { 22. I usually view my } \\
\text { performance as either a } \\
\text { complete success or a } \\
\text { complete failure. }\end{array}$ & & & & & & \\
\hline $\begin{array}{l}\text { 23. I feel badly about } \\
\text { myself when I am not } \\
\text { actively accomplishing } \\
\text { things. }\end{array}$ & & & & & & \\
\hline $\begin{array}{l}\text { 24. I have a hard time } \\
\text { forgiving myself when I } \\
\text { feel I haven't worked up } \\
\text { to my potential. }\end{array}$ & & & & & & \\
\hline
\end{tabular}




\section{Appendix D}

\section{2-Item Personal Norm of Reciprocity}

Positive Reciprocity subscale

Please read the following statements carefully and put an " $\mathrm{X}$ " in the appropriate box.

\begin{tabular}{|c|c|c|c|c|c|c|c|}
\hline & $\begin{array}{l}1 \\
\text { Strongly } \\
\text { Disagree }\end{array}$ & 2 & $\begin{array}{l}3 \\
\text { Disagree }\end{array}$ & $\begin{array}{l}4 \\
\text { Neutral }\end{array}$ & $\begin{array}{l}5 \\
\text { Agree }\end{array}$ & 6 & $\begin{array}{l}7 \\
\text { Strongly } \\
\text { Agree }\end{array}$ \\
\hline $\begin{array}{l}\text { 1. If someone does a favor for } \\
\text { me, I am ready to return it. }\end{array}$ & & & & & & & \\
\hline $\begin{array}{l}\text { 2. When someone does me a } \\
\text { favor, I feel committed to repay } \\
\text { him/her. }\end{array}$ & & & & & & & \\
\hline $\begin{array}{l}\text { 3. If someone lends me money } \\
\text { as a favor, I feel I should give } \\
\text { him/her back something more } \\
\text { than what is strictly due. }\end{array}$ & & & & & & & \\
\hline $\begin{array}{l}\text { 4. I go out of my way to help } \\
\text { somebody who has been kind to } \\
\text { me before. }\end{array}$ & & & & & & & \\
\hline
\end{tabular}




\author{
Appendix E \\ Optimization of Primary and Secondary Control Scale \\ Compensatory Primary Control subscale - help-seeking subfactor
}

For the following set of questions, please read each one carefully and decide how much it applies to you. Indicate whether the statement is never true, seldom true, sometimes true, often true or almost always true.

1. When I get stuck on a task, I don't hesitate asking others for advice.

$\begin{array}{clcll}1 & 2 & 3 & 4 & 5 \\ \text { Never true } & \text { seldom true } & \text { sometimes true } & \text { often true } & \text { almost always true }\end{array}$

2. When I cannot solve a problem by myself I ask others for help.

$\begin{array}{lllll}1 & 2 & 3 & 4 & 5 \\ \text { Never true } & \text { seldom true } & \text { sometimes true } & \text { often true } & \text { almost always true }\end{array}$

3. When difficulties become too great, I ask others for advice.

$\begin{array}{lllll}1 & 2 & 3 & 4 & 5 \\ \text { Never true } & \text { seldom true } & \text { sometimes true } & \text { often true } & \text { almost always true }\end{array}$

4. When obstacles get in my way, I try to get help from others.

$\begin{array}{lllll}1 & 2 & 3 & 4 & 5 \\ \text { Never true } & \text { seldom true } & \text { sometimes true } & \text { often true } & \text { almost always true }\end{array}$


Appendix F

Suicidal Behaviors Questionnaire-Revised

The following questions ask about a specific topic - whether you have ever thought about suicide. Many people have had thoughts of suicide. Please answer honestly. Your responses will be kept confidential.

NOTE: A list of mental health agencies that can help individuals having thoughts of suicide is included at the end of the survey.

Please select the statement or phrase that best applies to you.

(Note: codes in parentheses were not included in measure given to participants, but are included here to show how scores were later calculated)

Have you ever thought about or attempted to kill yourself?

1. Never (coded 1)

2. It was a brief passing thought (coded 2)

3. I have had a plan at least once to kill myself but I did not want to try it (coded 3)

4. I have had a plan at least once to kill myself and really wanted to die (coded 3)

5. I have attempted to kill myself, but did not want to die (coded 4)

6. I have attempted to kill myself, and really hoped to die (coded 4)

How often have you thought about killing yourself in the past year?

1. Never

2. Rarely (1 time)

3. Sometimes (2 times)

4. Often (3-4 times)

5. Very often (5 or more times)

Have you ever told someone that you were going to commit suicide, or that you might do it?

1. No $(\operatorname{coded} 1)$

2. Yes, at one time, but did not really want to die (coded 2)

3. Yes, at one time, and really wanted to die (coded 2)

4. Yes, more than once, but did not want to do it (coded 3)

5. Yes, more than once, and really wanted to do it (coded 3)

How likely is it that you will attempt suicide someday?

0. Never

1. No chance at all 
2. Rather unlikely

3. Unlikely

4. Likely

5. Rather likely

6. Very likely 